\title{
Membrane insertion of chromogranin B for granule maturation in regulated secretion
}

2 Gaya P. Yadav ${ }^{1, \#, ~ H a i y u a n ~ W a n g ~}{ }^{2, \#, ~ J o k e ~ O u w e n d i j k ~}{ }^{3}$, Mani Annamalai ${ }^{4}$, Stephen Cross ${ }^{5}$,

3 Qiaochu Wang 2 , D. Walker Hagan ${ }^{6}$, Clayton Mathews ${ }^{4}$, Edward A. Phelps ${ }^{6}$, Paul Verkade ${ }^{3}$,

$4 \quad$ Michael X. Zhu², and Qiu-Xing Jiang ${ }^{1 *}$

5

6 1. Department of Microbiology and Cell Science, University of Florida, 1355 Museum Drive,

7 Gainesville, FL 32611-0700, USA.

8 2. Department of Integrative Biology and Pharmacology, McGovern Medical School, The

9 University of Texas Health Science Center at Houston, 6431 Fannin St., Houston, TX 77030, 10 USA.

11 3. School of Biochemistry, Biomedical Sciences Building, University Walk, University of

12 Bristol, Bristol, BS8 1TD, UK.

13 4. Department of Pathology, College of Medicine, University of Florida, 1275 Center Drive,

14 Gainesville, FL 32611, USA.5. Wolfson Bioimaging facility, Biomedical Sciences Building,

15 University Walk, University of Bristol, Bristol, BS8 1TD, UK.

17 Gainesville, FL 32611, USA.

18

19 \# Authors of equal contributions

20 * Correspondence and lead contact: Qiu-Xing Jiang, PhD 
16

\section{Highlights:}

- Native CHGB is amphipathic and distributes in the lumen and membranes of secretory granules with contrastingly different destinies and functions.

- Native CHGB, once delivered to cell surface via granule exocytosis, dominates anion conductance in plasma membranes.

- CHGB channels facilitate granule acidification and cargo maturation in cultured and primary neuroendocrine cells.

- CHGB channels from bovine, rat and mouse cells all serve the long-missing, intraorganellar anion shunt pathway in the secretory granules for regulated secretion.

Short running title: $\mathrm{CHGB}$ as the shunt pathway in regulated secretion

Keywords: Regulated secretion, granule acidification, anion channel, cargo maturation, proinsulin-insulin conversion, insulin-secretory granules, catecholamine loading, dopamine, neurotransmitter release, type 2 diabetes, neurodegenerative diseases, neuroendocrine cancer Abbreviations: CHG: chromogranin; CHGB: chromogranin B; ISG: immature secretory granule; DCSG: dense-core secretory granule; TGN: trans-Golgi network; CLC: chloride channel / transporter; RRG: readily releasable granule; MIF: membrane-interacting fragment in the C-terminal half; CHGB-MIF: a membrane-interacting fragment at the C-terminal half of CHGB; CHGB- $\triangle$ MIF: CHGB deletion mutant lacking its MIF. 


\section{ABSTRACT}

2 Regulated secretion serves responses to specific stimuli in eukaryotes. An anion conductance was found

3 essential for maturation and acidification of secretory granules four decades ago, but its genetic identity

4 was unknown. We now demonstrate that chromogranin $\mathrm{B}(\mathrm{CHGB})$, an obligate granule protein,

5 constitutes the long-sought anion channel. High-pressure freezing immuno-electron microscopy and

6 biochemical assays showed native CHGB in close proximity to secretory granule membranes, and its

7 membrane-bound and soluble forms both reconstituted $\mathrm{Cl}^{-}$channels. Release of secretory granules

8 delivered CHGB clusters to plasma membranes, which dominate whole-cell anion conductance.

9 Intragranular $\mathrm{pH}$ measurements and cargo maturation assays found that CHGB channels supported

10 proinsulin - insulin conversion and dopamine-loading in neuroendocrine cells. $\beta$-cells from $C h g b^{-/-}$mice

11 exhibited significant granule deacidification, accounting for hyperproinsulinemia, altered glucose-

12 tolerance response and lower dopamine concentration in chromaffin granules in these animals. Membrane

13 insertion of well-conserved $\mathrm{CHGB}$ is thus indispensable for granule maturation in exocrine, endocrine

14 and neuronal cells. 


\section{INTRODUCTION}

2

3 Regulated secretion is conserved in the eukaryotic kingdom of life. As a major measure to

4 respond to external stimuli, eukaryotic cells rely on regulated secretion to generate local

5 feedbacks or remote regulations within a multicellular system or a commune of unicellular

6 organisms ${ }^{1}$. In human, exocrine and endocrine cells, neural cells, astrocytes, mesenchymal stem

7 cells, etc. may all utilize regulated secretion to achieve physiological homeostasis and regulation

$8 \quad{ }^{2-6}$. These cells produce specific bioactive cargo molecules that are densely packed in membrane-

9 enclosed intracellular compartments, whose mature forms are called dense-core secretory

10 granules (DCSGs). DSCGs differ from the lysosome-related organelles (LROs) ${ }^{7}$. Upon

11 reception of specific secretagogues, DSCGs are exocytosed to release their contents. The

12 released cargo molecules, such as peptide hormones, adrenaline, dopamine, etc. can act locally

13 on cells near the releasing sites (autocrine or paracrine), or those far away through the circulation

14 system (endocrine).

16 Both positive and negative signals from a variety of cell types are integrated together to achieve

17 a steady state at the systems level. Physiological studies have revealed multiple layers of

18 regulations through regulated secretion, making it critically important for every multicellular

19 tissue or organ inside a human body. At the level of individual cells, regulated secretion is finely

20 tuned. A well-known example is the two phases of insulin release after glucose challenge ${ }^{8,9}$. But

21 how each endocrine cell achieves a temporally-controlled, quantitative secretion remains largely

22 unresolved. 
1 Biogenesis of nascent secretory granules, sorting and maturation of immature granules, and

2 exocytotic release of mature granules are three main steps of regulated secretion ${ }^{1,10}$. Granule

3 biogenesis exhibits cell specificity and relies on various molecular players and signals in cells of

4 varying tissue origins ${ }^{11-13}$; however, its molecular mechanism remains unclear ${ }^{14}$, despite the

5 appealing hypothesis of protein aggregates-induced membrane budding and possible recruitment

6 of receptors and lipids (e.g. cholesterol) at exit sites of the trans Golgi network (TGN) ${ }^{10,15-20}$.

7 Exocytotic release of mature DCSGs utilizes $\mathrm{Ca}^{2+}$-triggered membrane fusion catalyzed by

8 specific SNARE complexes ${ }^{21-24}$, whose fundamental principles are well understood. Normal

9 maturation of secretory granules includes both homotypic fusion of immature secretory granules

10 (ISGs) and budding and removal of missorted or unwanted molecules. This maturation process is

11 accompanied by interior acidification from $\mathrm{pH} \sim 6.5^{\text {to }} \sim 5^{16,25}$. The molecular mechanisms for

12 sorting or removal of granular contents, luminal acidification, maturation of cargos and

13 packaging / concentrating of granular components are only partially defined.

15 Prior studies, mainly in chromaffin granules, suggested that normal maturation of nascent ISGs into DCSGs requires a vacuolar-type $\mathrm{H}^{+}$-ATPase (vATPase; also called vesicular ATPase) to

17 transport protons and a $\mathrm{Cl}^{-}$conductance to neutralize charge accumulation resulted from proton translocation ${ }^{25-28}$. The genes for the subunits of the proposed vATPase have been cloned, and its physiological functions are well characterized ${ }^{29,30}$. The proposed $\mathrm{Cl}^{-}$conductance, however, has

20 remained a mystery for more than 40 years. Organellar cation and anion channels have been

21 identified in all major intracellular membranes ${ }^{31-33}$. Inositol-1,4,5-trisphosphate receptors

$22\left(\mathrm{IP}_{3} \mathrm{Rs}\right), \mathrm{K}^{+}$channels, and CLC-type $\mathrm{Cl}^{-}$channels / transporters were proposed to reside in 23 secretory granule membranes, but these observations have conflicts or variations due to 
1 experimental conditions. Even though earlier studies found no cation permeation in chromaffin

2 granules ${ }^{27}$, patch clamp recordings from isolated granules revealed different $\mathrm{K}^{+}$channels, $\mathrm{IP}_{3} \mathrm{Rs}$,

3 a large-conductance $\mathrm{Cl}^{-}$channel and a few CLC-family members ${ }^{34-38}$. Due to inevitable

4 contamination of isolated secretory granules by other intracellular membranes, the physical

5 locations of these identified channels or transporters in intracellular membranes remain

6 uncertain. In addition, counter-arguments have been raised on whether luminal granular proteins

7 are sufficient to bind and shield all protons and buffer granular $\mathrm{pH}$ at an acidic level. Such a

8 mechanism is unlikely because without neutralization, the charged protons bound by cargo

9 molecules cannot be shielded by media or granular proteins, and should lead to a high positive

10 potential $(>+60 \mathrm{mV} \text { after only a small number of protons cross the membrane })^{25,27}$. A shunt

11 pathway is thus a must when large quantities of protons are required to acidify the high contents

12 of biomolecules inside DCSGs. Identifying the unknown shunt conductance with high certainty

13 is therefore critically important and will be the focus of this paper.

15 Members of the granin superfamily share low similarity in primary structures ${ }^{39}$ and form distinct phylogenetic subfamilies. Native CHGB aggregates strongly at low $\mathrm{pH}$ and with $\mathrm{mM} \mathrm{Ca}{ }^{2+}{ }^{40,41}$.

17 Partially purified CHGB binds strongly to lipid vesicles under certain conditions ${ }^{40}$. A "tightly membrane-associated form" of CHGB was observed on the surface of PC-12 cells after granule release, which resisted high-salt extraction, but was dissolved with detergents, indicating that

20 some of the rat $\mathrm{CHGB}$ protein might be integrated in membranes ${ }^{42}$. Genome-wide association

21 studies identified multiple mutations in human Chgb gene that are closely linked to Type 2 22 diabetes (T2D; supplementary Table S1) ${ }^{43}$, heart failure ${ }^{44-46}$, neurodegenerative diseases and 23 psychiatric disorders 47,48 . Mechanistically, indirect evidence implicated that intracellular CHGB 
1 might form proteinaceous aggregates at the TGN and drive the budding of nascent granular

2 vesicles ${ }^{19,49}$, although the genuine mechanism is yet to be defined. Studies of Chgb-null mice

3 by three groups reported tissue-specific variations regarding CHGB's uncertain physiological

4 roles in granule biogenesis 12, 13, 50-52. The physiological functions of intracellular CHGB in

5 regulated secretion remains largely unknown.

6

7 Recently we demonstrated that recombinant murine CHGB (mCHGB) alone suffices to form a 8 highly selective $\mathrm{Cl}^{-}$channel in artificial membranes ${ }^{14}$. Given the unknown identity of the $\mathrm{Cl}^{-}$

9 conductance in the regulated secretory pathway and the high conservation of CHGB proteins

10 from zebra fish to human, it is natural to ask whether native CHGB may be inserted in granular

11 membranes, function as an anion conductance and support normal granular acidification. Here

12 we investigated the intracellular function of the CHGB channel from six different aspects to

13 elucidate its physiological roles of its membrane-bound form in granule acidification and 14 maturation.

RESULTS

\section{CHGB puncta on INS-1 cell surfaces after exocytotic release of secretory granules}

19 The granin proteins in endocrine cells have long been considered and treated as soluble proteins

201,53 . Although this general view has been challenged by some experimental results $40,42,54$, it was

21 thought that the insoluble CHGB inside secretory granules resulted from $\mathrm{pH}$-dependent

22 association with membranes and partners. Surprisingly, our recent studies demonstrated that after

23 reconstitution nearly all recombinant mouse CHGB (mCHGB) protein purified from $S f 9$ cells are 
1 not peripherally associated with membranes, but instead are integrated to form anion channels ${ }^{14}$.

2 We thus asked whether native CHGB, despite multiple post-translational modifications including

3 glycosylation, phosphorylation and tyrosine-O-sulfation 55, 56 behaves the same as the

4 recombinant protein.

6 We first tested if native CHGB is retained on the INS-1 cell surface after the release of secretory

7 granules. INS-1 cells were treated with a high $[\mathrm{KCl}]$ solution to release readily releasable

8 granules (RRGs) via activation of voltage-gated $\mathrm{Ca}^{2+}$ channels (VGCCs) and $\mathrm{Ca}^{2+}$-dependent

9 exocytosis. The cells were then labeled with an anti-CHGB antibody under non-permeabilized

10 conditions followed by an Alexa 488-conjugated secondary antibody. Confocal fluorescence

11 microscopy (FM) at the focal level of the top cell surface revealed multiple rat CHGB (rCHGB)

12 puncta (Fig. 1A), demonstrating that after exocytosis rCHGB remained clustered, presumably, at

13 the exocytotic sites. This resembles the "tightly membrane-associated" rCHGB on PC-12 cells 42.

14 From quantification, the high KCl-treated cells have on average $\sim 19$ puncta in the image planes,

15 significantly higher than the control cells (2-3) or those cells stimulated with high $\mathrm{KCl}$ but

16 labeled with an antibody against the intracellular suppressor of cytokine signaling 1 (SOCS1)

17 ( 6) (Figs. 1B-C). Similarly, stimulation of INS-1 cells in suspension significantly increased

18 surface labeling by the CHGB antibody (supplementary Figs. S1A, B). A good fraction of native

19 CHGB is therefore retained on the surface of INS-1 cells upon granule release.

21 The presence of CHGB puncta on cell surface suggested that other membrane-associated

22 components of the secretory granules might not diffuse away quickly after exocytosis, either. To

23 verify this point, we further demonstrated that vATPase, another major component in the 
1 membranes of secretory granules, colocalizes with CHGB on the cell surface as puncta (Fig.

2 S1C). The clustered co-distribution of vATPase and CHGB apparently makes it convenient to

3 retrieve granular membranes and proteins from cell surface via endocytosis ${ }^{57}$.

4

5 Next, we asked whether the native CHGB retained on cell surface became membrane-attached

6 only during or after the granule release, but was fully soluble in the lumen before exocytosis. We

7 performed high-pressure freezing and immuno-electron microscopy (HPF immuno-EM) to

8 compare the distribution of native $\mathrm{rCHGB}$ with that of insulin in rat $\beta$-cells. HPF immuno-EM is

9 superior in keeping intact original cellular structures and revealing genuinely physiological

10 distribution of target molecules. Dual immunogold labelling of CHGB and insulin was

11 performed on high-pressure-frozen and Lowicryl HM20 freeze-substituted isolated rat islets of

12 Langerhans ${ }^{58-60}$. CHGB was labeled with 12-nm gold particles and insulin with 6.0-nm ones

13 (left column in Fig. 1D).

15 For quantitative analysis, the circumference of each granule was manually drawn (middle 16 column in Fig. 1D) before an automated plugin for Fiji was applied to mark the gold particles 17 and fill up the volume of the granule (right column in Fig. 1D). This allowed for automated 18 calculation of the shortest distance from each gold particle to the outer edge of the granule within 19 the section plane. A total of 324 granules from three independent experiments were analyzed 20 (Fig. 1E). As no obvious difference was observed between individual experiments, all data from

21 three were pooled. The average granule diameter was $296 \pm 82 \mathrm{~nm}$ (mean $\pm \mathrm{SD}$ ), which is 22 slightly larger than previously observed ${ }^{60}$. The distribution plots of nearest distances to granular 23 membranes, grouped in 20-nm bins, were obviously different between CHGB and insulin (Fig. 
1 1E). While insulin, soluble in granular lumen, showed an relatively even distribution with an

2 average distance of $116.6 \pm 62.2 \mathrm{~nm}$ (mean $\pm \mathrm{SD}$ ), CHGB exhibited an obviously skewed

3 distribution towards membrane, with $\sim 70 \% 12-\mathrm{nm}$ gold particles situated at $\leq 60 \mathrm{~nm}$ from the

4 nearest granular membranes and an average distance of $52.1 \pm 32.4 \mathrm{~nm}(\mathrm{p}<0.00001, t$-test with

5 unequal variances $)$. Given the dimensions of the $1^{\text {st }}$ and $2^{\text {nd }}$ antibodies $(\sim 25-30 \mathrm{~nm}$ together$)$, the

6 length of conjugation linkers and the sizes of the nanogolds, CHGB molecules integrated in the

7 membrane should be within $\sim 50 \mathrm{~nm}$ from the granular membranes (Fig. 1E). These results

8 indicate that contrary to insulin, native CHGB is more preferentially present at or near the

9 membranes of insulin-secretory granules in rat pancreatic $\beta$-cells. The native CHGB thus

10 probably exists in both membrane-associated and soluble forms inside the granules.

\section{Direct recordings of granular CHGB channels retained on cell surface}

13 To reconcile the membrane association of CHGB with its well-assumed solubility, Pimplikar and

14 Huttner proposed that CHGB must interact with other partners in membranes ${ }^{42}$. We recently

15 showed that when reconstituted in artificial membranes in vitro, recombinant mCHGB alone

16 suffices to form a chloride channel ${ }^{14}$. This brings up the intriguing possibilities that native

17 CHGB may be inserted into granular membranes and form anion channels, too. The native

18 CHGB puncta in plasma membranes may reflect at least a good portion of membrane-bound

19 proteins, which would become exposed to the extracellular side after soluble granular contents

20 diffuse away. If so, the putative CHGB channels in the puncta should be accessible for

21 electrophysiological recording. To test this prediction, we performed whole-cell patch-clamp

22 recordings of $\mathrm{PC}-12$ cells with pipette and bath $\left[\mathrm{Cl}^{-}\right]$set at $6.0 \mathrm{mM}$ and $152 \mathrm{mM}$, respectively.

23 With the cell being held at $-80 \mathrm{mV}$, a voltage protocol made of a ramp from -80 to $+80 \mathrm{mV}$ in 
$1 \quad 100 \mathrm{~ms}$, a $50-\mathrm{ms}$ step at $80 \mathrm{mV}$ and a $400-\mathrm{ms}$ step to $0 \mathrm{mV}$ was applied every second. The

2 depolarization voltages activated VGCCs to facilitate $\mathrm{Ca}^{2+}$ influx, and thus triggered release of

3 RRGs via $\mathrm{Ca}^{2+}$-dependent membrane fusion. Accordingly, we detected an increase of outwardly

4 rectifying currents in the presence of $2.5 \mathrm{mM} \mathrm{Ca}^{2+}$ outside, but not when $\mathrm{Ca}^{2+}$ was absent (Figs.

$52 \mathrm{~A}, 2 \mathrm{C}$ ). The currents exhibited a negative reversal potential ( $b$ in Fig. 2B) and the outward

6 currents were largely abolished by removal of extracellular $\mathrm{Cl}^{-}$(Figs. 2A-B), suggesting that they

7 carried mostly $\mathrm{Cl}^{-}$. After $\sim 5$ minutes of repetitive stimulation, the current reached a maximum

8 (time point $b$ in Fig. 2A), which presumably reflects the full depletion of all RRGs.

The residual currents after substitution of extracellular $\mathrm{Cl}^{-}$with gluconate could stem from either

11 some cation conductance or some, albeit weak, permeation of gluconate through the anion

12 channels. Either of the two would cause a right shift of the experimental reversal potential from

13 the calculated Nernst potential of $\sim-82 \mathrm{mV}$ for $\mathrm{Cl}^{-}$. From the measured reversal potential of -40

$14 \mathrm{mV}, \mathrm{Cl}^{-}$conductance would be 5 times of that for monovalent cations (including leak) if there

15 was no gluconate permeation, or the anion channel had a $\mathrm{Cl}^{-}$: gluconate permeability ratio of 6:1

16 if all recorded currents were from the same type of anion channels. Realistically, in the presence

17 of small leak and gluconate permeation, $\mathrm{Cl}^{-}$currents should contribute to more than $85 \%$ of the

18 measured current increase after RRG release (Fig. 1A).

20 To assess if granular CHGB is responsible for the exocytotic increase in $\mathrm{Cl}^{-}$conductance in the 21 plasma membrane, we knocked down CHGB expression before making electrical recordings 22 (Fig. 2D; supplementary Figs. S2A-C) ${ }^{12}$. CHGB siRNAs suppressed CHGB expression by $>$ $2398 \%$ (Figs. S2A-B). Among four CHGB siRNAs in the mixture, each alone efficiently knocked 
1 down CHGB, with siRNAs 2 and 4 being $\sim$-fold more effective than the other two (Fig. S2C).

2 Thus, siRNAs 2 and 4 were used either individually or in combinations in different experimental

3 repeats. The same results from these repeats suggested no obvious OFF-target effects. We hence

4 pooled together data from cells treated by individual and combined siRNAs in quantitative

5 analysis. In CHGB knockdown INS-1 cells, we also compared the release of granules after

6 treatment with high $[\mathrm{KCl}]$ by detecting vATPase on cell surfaces (Fig. S2D vs. Fig. 1A), and

7 found that similar to pancreatic hormone release in islets isolated from $\mathrm{Chgb}^{-/}$mice ${ }^{13}$, CHGB

8 knockdown still allows delivery of vATPase in surface puncta, though to a lesser extent, after

9 depolarization-triggered granule release.

11 Next we compared the development of depolarization-induced $\mathrm{Cl}^{-}$currents in $\mathrm{PC}-12$ cells

12 transfected with control (sequence scrambled) or CHGB siRNAs. This time, an NMDG-Cl

13 pipette solution was employed to minimize outward cation currents. While the currents increased

14 steadily over time in cells transfected with the control siRNAs, they never did so in those

15 transfected with the CHGB siRNAs (Fig. 2D-E). These data demonstrate that the appearance of

$16 \mathrm{Cl}^{-}$conductance on the cell surface following the release of RRGs in PC-12 cells is dependent on

17 the expression of CHGB protein.

19 Notably, CHGB knockdown significantly decreased the number of intracellular granules in INS-

201 (Figs. S3A, S3E) and PC-12 cells that were stained with DND-160 (Fig. S3F). In PC-12 cells, a

$21 \sim 50 \%$ decrease in the average number of secretory granules per cell after CHGB knockdown is

22 comparable to the $\sim 30 \%$ reduction in granule content released from Chgb-null chromaffin cells

2361 . Because granule exocytosis remained normal in Chgb-/- cells (Fig. S2D) ${ }^{50,52}$, a $50 \%$ decrease 
1 in granule number was expected to incur $\sim 50 \%$ loss of $\mathrm{Cl}^{-}$currents in the CHGB-knockdown

2 cells should the $\mathrm{Cl}^{-}$conductance be contributed by another protein. However, we observed nearly

$3100 \%$ loss of $\mathrm{Cl}^{-}$currents, congruent with $\mathrm{CHGB}$ directly contributing to the $\mathrm{Cl}^{-}$conductance

4 carried to plasma membranes by RRGs. If the single channel conductance of a native CHGB

5 channel (in $150 \mathrm{mM} \mathrm{Cl}^{-}$) is similar to that of the recombinant one, $\sim 125 \mathrm{pS}{ }^{14}$, at least 300

6 channels ought to be delivered to produce a steady-state, whole-cell $\mathrm{Cl}^{-}$current of $\sim 4.5 \mathrm{nA}$ at +80

$7 \mathrm{mV}$.

8

9 Both membrane-bound and soluble CHGB proteins from bovine pancreatic secretory

10 granules are capable of reconstituting anion channels

11 Although native CHGB functions as a $\mathrm{Cl}^{-}$channel on cell surface after granule release (Fig. 2)

12 and recombinant $\mathrm{CHGB}$ forms a $\mathrm{Cl}^{-}$channel in vitro ${ }^{14}$, it remained unresolved whether $\mathrm{CHGB}$ in

13 fully sealed secretory granules inside a cell indeed functions as a channel, instead of forming a

14 channel during or after exocytic membrane fusion, and if so, whether it serves as the long-sought

15 anion conductance that supports granule acidification. In native cells CHGB undergoes various

16 posttranslational modifications, experiences contrastingly different lipid environments in

17 secretory granules and interacts with various partners and granular cargos, all of which might

18 disrupt its channel function. Because native secretory granules are on average $\sim 300 \mathrm{~nm}$ in

19 diameter (Fig. 1D), too small to be assessed by direct patch-clamp recording, we approached this

20 critical question from three orthogonal aspects: 1) biochemical analysis of native proteins from

21 isolated secretory granules, 2) granule maturation in cultured neuroendocrine cells and 3)

22 granular acidification in pancreatic $\beta$-cells of acutely isolated islets of Langerhans. 
1 To evaluate whether native bovine CHGB (bCHGB) inside secretory granules has the capacity to

2 form $\mathrm{Cl}^{-}$channels, we isolated secretory granules from bovine pancreas ${ }^{62,63}$. The soluble

3 contents inside the granules were released in three freeze-thaw cycles. Roughly equal amounts of

4 bCHGB proteins were detected in soluble and membrane-bound fractions (Fig. S4), in accord

5 with previous reports ${ }^{42,} 53$. In SDS-PAGE, mature bCHGB ran at $\sim 100 \mathrm{kDa}$ (Figs. S4, 3A-B, 3H-

6 I), probably due to posttranslational modification. In size-exclusion chromatography (SEC), the

7 membrane-bound bCHGB was eluted at the same position as the recombinant mCHGB dimers ${ }^{14}$.

8 The bCHGB hence behaves biochemically similar to the recombinant protein from $S f 9$ cells.

9

To examine if the purified bCHGB can form $\mathrm{Cl}^{-}$channels, both soluble and membrane-bound forms were purified in detergents and reconstituted into $\mathrm{KCl}$-loaded vesicles to measure channel activity by a light-scattering-based flux assay ${ }^{14}$. The assay detects increased Stokes radii of vesicles after sudden $\mathrm{KCl}$ efflux. In vesicles containing DOPC, sphingomyelin and cholesterol, the membrane-bound bCHGB yielded robust $\mathrm{Cl}^{-}$flux (Fig. 3D, $0.0 \mathrm{mM} \mathrm{Cl}$ ). Increasing extravesicular $\left[\mathrm{Cl}^{-}\right]$from 0.2 to $2.0 \mathrm{mM}$ (Fig. 3D) gradually decreased $\mathrm{Cl}^{-}$flux to nil, revealing an apparent $\mathrm{Cl}^{-}$-binding affinity of $0.47 \mathrm{mM}$ (Figs. 3D, E), which is almost the same as that of the recombinant $\mathrm{mCHGB}$ channels in egg PC vesicles $(0.49 \mathrm{mM}){ }^{14}$. DIDS, an anion channel blocker, inhibited bCHGB channel activity with an apparent $k_{D} \sim 0.43 \mu \mathrm{M}$ and a Hill coefficient, $n$, of $\sim 1.0$ (Figs. 3F-G), also nearly identical to what's measured for mCHGB. The native bCHGB channel is thus pharmacologically equivalent to the recombinant one.

As recombinant $\mathrm{mCHGB}$ does, the amphipathic nature of bCHGB allows its soluble form to reconstitute $\mathrm{Cl}^{-}$channels in membrane. After purification the soluble bCHGB showed similar 
1 band patterns as the membrane-bound form (Fig. $3 \mathrm{H}$ vs. 3A), despite more degradation products

2 (lane 2 in Figs. 3H-I). However, the full-length bCHGB still accounts for the majority of the total

3 protein (>80\%; Fig. 3I). Reconstitution of soluble bCHGB was incomplete when vesicles were

4 assayed after floatation in a density gradient (top in Fig. 3J) ${ }^{14}$. Quantification of bCHGB bands

5 in Coomassie blue-stained gels showed slightly higher reconstitution efficiency of membrane-

6 bound CHGB than the protein from the soluble fractions (Fig. 3J, bottom panel, red vs. blue

7 traces). Nonetheless, the soluble bCHGB reconstituted in vesicles yielded robust $\mathrm{Cl}^{-}$-flux,

8 comparable to that generated by vesicles made with the same amounts of membrane-associated

9 protein (mem-associated vs. soluble; Fig. 3K). Control experiments using empty vesicles yielded

10 negative results. In summary, both soluble and membrane-bound bCHGB proteins extracted

11 from bovine pancreatic granules are equally capable of reconstituting $\mathrm{Cl}^{-}$channels that are

12 pharmacologically equivalent to the recombinant mCHGB channels.

14 CHGB channel supports normal granular maturation in insulin-secretory cells

15 In the second set of experiments, we assessed the possible physiological roles of native CHGB

16 inside secretory granules in cultured cells. We reasoned that if CHGB serves as the long-sought

17 shunt pathway for $\mathrm{Cl}^{-}$, disrupting its function should slow down or even abolish acidification and

18 maturation of secretory granules. To test this prediction, we knocked down CHGB expression

19 and measured intragranular $\mathrm{pH}$. INS-1 cells were selected as the first model system because they

20 recapitulate insulin secretion as native pancreatic $\beta$-cells and their intragranular $\mathrm{pH}$ levels have

21 been extensively studied with a well-established procedure using DND-160, a ratiometric $\mathrm{pH}$

22 sensor $^{64}$. 
1 We first confirmed that DND-160 stains well the secretory granules in INS-1 cells. A

2 fluorescently-labeled granular protein, syncollin-pHluorin ${ }^{65}$, was transiently expressed and

3 imaged together with DND-160-stained compartments in live cells (Fig. S4A). By confocal

4 microscopy, DND-160-stained compartments all showed strong signals of syncollin, suggesting

5 that they are indeed secretory granules ${ }^{64}$. Because of the possible variations in DND-160 loading

6 among different granules, ratiometric measurements from dozens to hundreds of granules (Figs.

7 4A-D, S3B-D) were acquired in order to compare the distribution of $\mathrm{pH}$ values systematically.

8 Furthermore, when INS-1 cells loaded with DND-160 for 5 minutes were compared with those

9 loaded for 30 minutes, the measured distribution of intragranular $\mathrm{pH}$ was the same. Dye loading

10 for 5 minutes was thus sufficient for our experiments.

12 To evaluate the importance of CHGB channels to granular acidification, we knocked down

13 CHGB expression in INS-1 cells before overexpressing full-length mCHGB or its non-

14 conducting deletion mutant (CHGBAMIF). For DND-160, dual-excitation (Figs. S3B-D) and

15 dual-emission experiments (Figs. 4A-D) produced similar results. Comparison of cells

16 transfected with control- (CTL) or CHGB-specific siRNAs showed that CHGB knockdown

17 reduced the total number of secretory granules per cell (Figs. 4A, 4D, S3E-F) and increased

18 average intragranular $\mathrm{pH}$ (called deacidification; Figs. 4A-B, S3C-D). In dual excitation

19 experiments, cells treated with $\mathrm{NH}_{4} \mathrm{Cl}$ served as a positive control because $\mathrm{NH}_{4}^{+}$increases

20 intragranular $\mathrm{pH}$ to a neutral or slightly basic level. The $\mathrm{pH}$ distributions among 100-140

21 granules randomly selected from paired images of multiple cells (details in Supplementary

22 Information) showed an obvious deacidification after $\mathrm{NH}_{4} \mathrm{Cl}$ treatment (Figs. S3C-D), and the

23 CHGB knockdown shifted the $\mathrm{pH}$ distribution in the same direction (Figs. 4B, S3C). The 
1 average $\mathrm{pH}$ in the secretory granules that remained after CHGB knockdown in INS-1 cells

2 ( 30\%; Fig. S3E) was significantly higher than that from CTL siRNA-transfected cells (red vs.

3 grey in Fig. S3D). Similar results were obtained from dual-emission experiments (Figs. 4A-B).

4 Therefore, we focused on the dual emission experiments to avoid near-UV excitation.

6 After transient expression of wild-type CHGB and CHGB $\triangle$ MIF in CHGB-knockdown cells, we 7 repeated intragranular $\mathrm{pH}$ measurement (rows 3 \& 4 in Fig. 4A; Figs. 4C-D). Both constructs

8 contained the N-terminal sorting signal (Cys-loop) needed for protein sorting and granule

9 biogenesis ${ }^{20}$. The overexpressed proteins thus restored the number of granules (rows $3 \& 4$ vs.

10 row 2 in Fig. 4A, Fig. 4D), confirming that the recombinant mRNAs overwhelmed siRNAs for

11 protein expression. However, ratiometric $\mathrm{pH}$ measurements found that only the wild-type

12 CHGB, but not the non-conducting CHGBAMIF mutant, restored granular acidification (Figs. 4C, E). The overexpressed CHGB $\triangle \mathrm{MIF}$ even showed dominant negative effects (Fig. 4E). These

14 data demonstrate that the channel function of native CHGB, not its activity in granule biogenesis, 15 is required for normal granule acidification in INS-1 cells.

17 Because vATPase pumps protons, we tested whether CHGB knockdown caused deacidification 18 by reducing its expression. Western blotting showed that ATP6V0A2 expression was not changed by knockdown or by overexpressing CHGB or CHGB $\triangle \mathrm{MIF}$ (Fig. 4F), ruling out the possibility that the impaired granule acidification resulted from decreased vATPase level. As a

21 control, we measured intragranular $\mathrm{pH}$ using NPY-ClopHensor ${ }^{66}$, which was co-expressed with 22 CHGB or CHGB $\mathrm{M}$ MIF for ratiometric measurements (Fig. S5). An in situ calibration curve (Fig. $23 \mathrm{~S} 5 \mathrm{~B}$ ) was obtained to read out intragranular $\mathrm{pH}$ values in INS-1 cells overexpressing CHGB and 
1 CHGB $\triangle \mathrm{MIF}$, which on average were $\sim 5.5$ and $\sim 6.6$ respectively (Fig. S5C), similar to the results

2 from DND-160-stained granules (Fig. 4E). As observed in CHGB knockdown cells

3 overexpressing CHGB $\Delta$ MIF (Figs. 4A, 4E), CHGB $\Delta$ MIF exhibited a dominant negative effect,

4 likely through oligomerization with endogenous CHGB in forming tetrameric channels and making them nonfunctional. A second control is on granule biogenesis induced by CHGB $\Delta \mathrm{MIF}$.

6 When overexpressed in HEK293T and $\mathrm{Npcl}^{-/-} \mathrm{CHO}$ cells, both CHGB and CHGBAMIF and

7 their fusion proteins with ClopHensor induced granule-like vesicles that were stained with DND-

8160 (Figs. S6A-B), reassuring that CHGB $\triangle$ MIF is as good as wild-type CHGB in supporting 9 granule biogenesis (Fig. 4A).

11 Because of lower prohormone convertase activity at elevated $\mathrm{pH}$ levels ${ }^{67}$, loss of granule 12 acidification should impair proinsulin-to-insulin conversion (insulin maturation). Western blotting showed that in contrast to CTL, CHGB knockdown in INS-1 cells drastically reduced total insulin (proinsulin plus insulin) level, which was restored by overexpressing either CHGB or CHGB $\Delta \mathrm{MIF}$ in the knockdown cells (Figs. 4G, 4H). Thus, the effect on total insulin is related to the capacity of $\mathrm{CHGB}$ (or CHGB $\triangle \mathrm{MIF}$ ) in inducing granule biogenesis (Fig. $4 \mathrm{H}$ top). More

17 interestingly, CHGB knockdown impaired insulin maturation, as shown by the lack of mature 18 insulin band (Fig. 4G) and the insulin / proinsulin (Ins / ProIns) ratio being close to nil (Fig. 4H, bottom). While overexpression of wild-type CHGB corrected the defect in insulin maturation, CHGB $\Delta$ MIF expression did not (green vs. blue; Fig. 4H bottom). Because CHGB $\Delta$ MIF conducts no $\mathrm{Cl}^{-}$, it could not restore granule acidification or insulin maturation. The roles of CHGB in

22 granule acidification and maturation are thus tightly coupled, and match with the characteristics 23 of the unknown $\mathrm{Cl}^{-}$conductance first proposed in chromaffin granules ${ }^{25,27}$. 
2 Native CHGB channel facilitates normal dopamine loading in PC-12 cells

3 To evaluate how generally the CHGB channel functions for granule acidification and maturation,

4 we performed similar experiments in PC-12 cells and compared intragranular pH's among four

5 differentially treated cells (Figs. S7, 5A-C). Similar to INS-1 cells, CHGB knockdown in PC-12

6 cells decreased the number of secretory granules (Figs. S3F and S7), which was restored by

7 CHGB or CHGB $\triangle$ MIF (Fig. S7). CHGB knockdown de-acidified secretory granules in PC-12

8 cells (Figs. 5A-B), which was reversed by overexpressing wild-type CHGB, but not CHGB $\Delta$ MIF

9 (Figs. 5A, 5C). Manipulations in PC-12 did not alter ATP6V0A2 expression, either (Figs. 5D).

10 Therefore, like INS-1 cells, PC-12 cells rely on CHGB channel activity for normal granule

11 acidification.

Dopamine is the main cargo inside the secretory granules of PC-12 cells. It is pumped into 14 granules by a $\mathrm{H}^{+}$-coupled vesicular monoamine transporter (vMAT) (Fig. 5F) ${ }^{68}$. Granular deacidification in PC-12 cells is expected to decrease dopamine content in RRGs. ELISA measurements ${ }^{69}$ showed that CHGB knockdown significantly decreased dopamine content in

17 RRGs, which was recovered by overexpressing wild-type CHGB, but not the non-conducting CHGB $\triangle$ MIF (Fig. 5E). In accord with our data, decreased granular dopamine content was observed in $\mathrm{Chgh}^{-/}$chromaffin cells ${ }^{50,61}$, although these groups attributed it to abated dopaminebinding capacity of granular matrix. Based on our analysis, granule deacidification-induced

21 suppression of dopamine loading would probably be the real cause. 
1 Although CLC-3 was known to be absent in the secretory granules, we still examined whether in

2 our experimental systems, the physiological effects of CHGB had contributions from CLC-3 or

3 CLC-5. Among INS-1 cells transfected with siRNAs targeting CHGB, CLC-3 or CLC-5, only

4 CHGB siRNAs caused granule deacidification (Fig. 5G), suggesting that neither ClC-3 nor CLC-

55 serves as the key anion channel for granule acidification. By western blotting, the CLC-3

6 siRNAs were founded highly effective and specific in knocking down CLC-3 expression without

7 affecting CHGB (Fig. 5H vs. 5I). Inversely, CHGB siRNAs had no effect on CLC-3 expression,

8 either (Fig. 5I). Therefore, the effect of CHGB knockdown on granule acidification did not occur

9 by indirectly altering CLC-3 (or -5) expression, but did so by directly suppressing CHGB 10 channels.

\section{Primary pancreatic $\beta$-cells from $\mathrm{Chgb}^{-/-}$mice display impaired granule acidification}

13 Previously, CHGB-knockout mice were reported to exhibit reduced storage and release of 14 catecholamines from chromaffin cells $12,13,50$ and a decreased level of stimulated secretion of 15 insulin and other pancreatic hormones from islets (Obermuller et al., 2010). Because pancreatic 16 islets of Chgb-null animals appeared unable to compensate well for the CHGB loss (Obermuller

17 et al., 2010), we used them to evaluate whether CHGB knockout leads to impaired granule acidification in primary $\beta$-cells, which in turn elicits neuroendocrine phenotypes in the mutant mice. A Chgb/- mouse strain produced by the Wellcome Trust Sanger Institute and distributed by

20 EMMA (Figs. 6 \& S8; \#10088 at URL: https://www.infrafrontier.eu/) was raised by the UF

21 animal care service. All animal work followed an IACUC-approved protocol. Genotyping was

22 performed by PCR using primers recommended by the Sanger Institute (Fig. S8). Pancreatic 23 islets were isolated from mice of $\sim 8$ weeks or older. Male and female littermates were analyzed 
1 separately in order to identify any sex-related differences. Intragranular $\mathrm{pH}$ in pancreatic $\beta$ cells

2 was measured either in isolated islets (Figs. 6B-D) or in $\beta$-cell monolayers derived from these

3 islets (Figs. 6E-G). Fig. 6A shows representative images of isolated islets. Western blotting of

4 CHGB in liver tissues from $C h g b^{+/+}$and $C h g b^{-/-}$mice confirmed the loss of CHGB protein in the

5 latter. Western blotting was also performed for other tissues to confirm complete penetrance of

6 the knockout.

8 For whole islet imaging, freshly isolated islets were cultured for two days before DND-160

9 staining and imaging. To avoid variations in DND-160 staining of cells away from islet surfaces,

10 we focused on cells closer to the surface. Compared to $C h g b^{+/+} \beta$-cells (top row in Fig. 6B),

$11 \mathrm{Chgh}^{-/} \beta$-cells contained fewer well-stained, bright granules (bottom row; Fig. 6B), agreeing

12 with decreased granule biogenesis and deacidification as observed in INS-1 and PC-12 cells

13 (Figs. S3E-F, 4E, 5A). The distribution of intragranular $\mathrm{pH}$ measured from hundreds of granules

14 showed clear shift to higher values in $C h g b^{-/-} \beta$-cells from both male and female mice (Fig. 6C).

15 The average intragranular $\mathrm{pH}$ values in $C h g b^{-/} \beta$-cells are significantly higher by $\sim 0.7 \mathrm{pH}$ units

16 than those in wild-type cells (Fig. 6D), demonstrating that the lack of CHGB rendered substantial

17 deacidification of insulin-secretory granules in pancreatic $\beta$-cells of both sexes (Figs. 6C-6D).

18 Deacidification by $\sim 0.7 \mathrm{pH}$ units may slow down proinsulin-insulin conversion enough to

19 account for the previously observed increase of proinsulin release from $C h g b^{-/}$islets ${ }^{13}$. As a

20 control, we confirmed that in $C h g b^{-/}$pancreatic islets, CLC-3 expression was not decreased, but

21 instead increased slightly (Fig. 6F). Therefore, the observed granule deacidification in $C h g b^{-/-} \beta-$

22 cells was not secondary to a loss of CLC-3. 
1 As an alternative of $\mathrm{pH}$ measurement in islet cells, we prepared cultured $\beta$-cell monolayers

2 following an established protocol ${ }^{70}$ and transiently expressed NPY-ClopHensor fusion protein

3 (Fig. S5) in them for $\mathrm{pH}$ measurement (Figs. 6E, 6G). Significant granular deacidification was

4 observed with the difference in average intragranular $\mathrm{pH}(\sim 1.5 \mathrm{pH}$ units $)$ between $C h g b^{-/-}$and

5 wild-type cells being greater than that ( $\sim 0.7 \mathrm{pH}$ units) from DND-160-stained islet cells (Fig. 6G

6 vs. 6D). These results reassured impaired acidification of secretory granules in $C h g b^{-/}$cells,

7 which underlies the defective insulin maturation in and elevated proinsulin release from the islets

8 of $\mathrm{Chgh}^{-/-}$mice ${ }^{12,13,50}$.

9

10

\section{DISCUSSIONS}

12

13

14

15

16

17

18

19

20

21

22

\section{CHGB-membrane insertion and channel activity in native secretory granules}

From six different angles, our data congruently demonstrate a major physiological function of native full-length $\mathrm{CHGB}$ in serving as the long-sought $\mathrm{Cl}^{-}$conductance in secretory granules that supports normal granule acidification and maturation. The identity of such a conductance has been elusive for more than four decades and the candidate approach in the past failed to identify it ${ }^{25}$. The amphipathic nature of the CHGB channel, differing from all known canonical anion channels, made it evade all previous efforts. As far as we know, the channel function is the first well-grounded intracellular function of the CHGB subfamily of granins. Among all amphipathic proteins that form ion channels, CHGB is the first that shows exquisite anion selectivity. 
1 Despite multiple posttranslational modifications, native CHGB remains amphipathic and exists

2 in soluble and membrane-associated forms, both of which reconstitute anion channels in

3 membranes. The native channels retain the same high sensitivity to DIDS and luminal $\left[\mathrm{Cl}^{-}\right]$

4 (Figs. 3E, 3G). After granule release, the membrane-associated CHGB channels remain as

5 clusters in the plasma membranes and conduct $\mathrm{Cl}^{-}$. Because normal cells have sufficient surface

6 area in ER membranes, nascent CHGB could be membrane-associated in ER as well; but it is

7 unclear whether it functions as a channel in ER (or Golgi). In DCSGs, CHGB is concentrated

8 and may induce the formation of nanoparticles or nanotubules as the recombinant protein does ${ }^{14}$.

9 Its soluble forms are likely stabilized by self-oligomerization or forming complexes with other

10 proteins or lipids (Figs. 1D \& 3H). The "tightly membrane-associated" CHGB channels keep

11 granular transmembrane potential close to the Nernst potential of $\mathrm{Cl}^{-}$and neutralize luminal

12 positive charges translocated by vATPase. After RRG release, hundreds of CHGB channels are

13 delivered to the surface of each PC-12 cell, making the cell membrane highly permeable to $\mathrm{Cl}^{-}$.

14 We postulate that the high $\mathrm{Cl}^{-}$selectivity of the $\mathrm{CHGB}$ channel prevents intracellular anionic

15 metabolites from being passively concentrated into secretory granules and being dumped as

16 waste via exocytosis, or when delivered to cell surface, it stops small organic metabolites inside

17 the cell from diffusing out. In $\mathrm{Chgb}^{-/-}$cells, the lack of $\mathrm{Cl}^{-}$influx impedes the neutralization of

18 luminal positive charge, stops continued proton pumping ${ }^{71}$, impairs granule acidification, delays

19 proinsulin-insulin conversion in INS-1 and $\beta$-cells (Fig. 7A) and decreases $\mathrm{H}^{+}$-coupled pumping

20 of dopamine into secretory granules in PC-12 cells (Fig. 7B). These deficits were corrected by

21 overexpressing wild-type CHGB, but not the non-conducting CHGB $\triangle \mathrm{MIF}$. 
1 Consistent with impaired granule acidification in $C h g b^{-/-}$mice, hyperproinsulinemia and insulin

2 secretion defects under glucose challenge were reported before in these animals ${ }^{13}$. A significant

3 decrease of catecholamine content was observed in chromaffin granules ${ }^{50}$, and the deficiency

4 was attributed to an unknown intracellular mechanism leading to saturation of catecholamine-

5 binding capacity at the luminal side ${ }^{50}$. Instead, our model depicts a new mechanism --- the lack

6 of CHGB channel activity de-acidifies chromaffin granules and thereby diminishes the driving

7 force for catecholamine loading and decreases steady-state concentration of monoamines inside

8 the granules (Fig. 7B). Furthermore, under the same principle of electroneutrality, the $\mathrm{CHGB}^{-}$

9 conductance, which conducts well in both directions (Fig 2B), may facilitate $\mathrm{Ca}^{2+}$ release from

10 secretory granules or $\mathrm{Ca}^{2+}$ influx from the extracellular side, both of which could accelerate RRG

11 release because elevation of local $\left[\mathrm{Ca}^{2+}\right]$ is a prerequisite for granule exocytosis (Figs. 2A, 2C).

12 Our simplified mechanism cannot explain why only a small fraction $(0.5 \%$ in mouse $\beta$-cells $)$ of

13 mature DCSGs are readily releasable ${ }^{9}$. Moreover, in $C h g b^{-/}$mice, compensatory expression of

14 other conductances or time-integral of slow granule maturation (due to membrane leaks) may

15 partially mitigate the deacidification phenotypes, which makes $C h g b^{-/}$mice seemingly healthy

16 under the breeding conditions. Given the importance of regulated secretion, existence of intrinsic

17 compensation is not surprising. Identification of these compensatory molecules and mechanisms

18 will be interesting for future studies.

20 Our observations in cultured neuroendocrine cells and primary $\beta$-cells explain the main

21 phenotypes of $\mathrm{Chgh}^{-/-}$mice --- hyperproinsulinemia and decreased catecholamine content in

22 chromaffin granules $12,13,50$. Future studies will need to examine whether the missense CHGB

23 mutations genetically associated with Type 2 diabetes, neuroendocrine or neurodegenerative 
1 diseases alter the channel function, granule acidification and maturation, or release ${ }^{12}$.

2 Overexpression of CHGB and CHGA has been observed in a large array of human

3 neuroendocrine cancer tissues ${ }^{72}$, but their functional significance remains a mystery.

4 Verification of a causative relation between altered CHGB channel function and these human

5 diseases will likely make the channel a good target for new therapeutics.

6

7 CHGB differs from all other dimorphic proteins in forming highly selective anion channels.

8 Multiple soluble proteins can be inserted into membranes and form large non-selective

9 conductances that are usually pathogenic or cytotoxic. Many hemolysins are pore-forming

10 toxins. S. aureus $\alpha$-toxin, for example, is secreted as monomers and oligomerizes in host cell

11 membranes to form multimeric complexes which contain non-selective, large-conductance, beta-

12 barrel pores ${ }^{73,74}$. C-type lectins are released from small intestine epithelial cells as monomers

13 and are activated by proteolytic removal of their N-terminal peptides before forming hexameric

14 pores in membranes of $G^{+}$bacteria ${ }^{75,76}$. VopQ, a pathogenic effector protein of the Vibrio

15 species, is released inside the infected cells and punctures lysosomal membranes via forming

16 non-selective large-conductance channels to cause cell demise ${ }^{77,78}$. Other examples include

17 CLIC family proteins (whose physiological functions remain not fully settled) ${ }^{79-83}$, the membrane-attack complex formed by the $\mathrm{C} 5 \mathrm{~b} / \mathrm{C} 6-9$ in the complement pathways ${ }^{84-89}$, the channel forming colicins ${ }^{90-92}$, the pore forming Gasdermin D (GSDMD) in pyroptosis ${ }^{93-97}$, the pore-forming $\mathrm{BAK}$ or $\mathrm{BAX}$ in outer mitochondrial membrane that releases cytochrome $\mathrm{C}$ during apoptosis ${ }^{98-101}$, the membrane-permeabilization through the pores formed by phosphorylated MLKL during necroptosis ${ }^{102-106}$, the pore-forming microbiocidal defensins ${ }^{107-109}$, etc. All the membrane-spanning pores formed by these well-studied proteins are non-selective and almost 
1 always cytotoxic via breakdown of transmembrane ionic gradients and loss of nutrients, ATP and

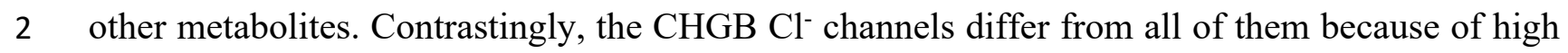

3 anion selectivity and the physiological, instead of pathological, roles in the regulated secretory

4 pathways in exocrine, endocrine and neuronal cells. The more stringent anion selectivity is

5 obviously important in order to prevent the breakdown of ion gradients across membranes of the

6 regulated secretory pathway, and minimize the post-exocytotic loss of organic anionic

7 metabolites that are abundant inside these cells.

8

9 CHGB's physiological functions in granule biogenesis, maturation and release

10 Being one of the most abundant proteins and present almost in every human tissue, CHGB was

11 previously assumed to participate in every step of the regulated secretory pathway. Its N-terminal

12 Cys-loop serves as a sorting signal ${ }^{110,111}$. Its $\mathrm{Ca}^{2+}$-induced aggregates ${ }^{14}$, together with other

13 proteins and cargos at the TGN, may induce membrane budding for granule biogenesis.

14 Aggregation may keep a major fraction of $\mathrm{CHGB}$ in its soluble form (Figs. 1D-E). High-

15 concentrations of $\mathrm{Ca}^{2+}$ or $\mathrm{Zn}^{2+}$ inside secretory granules may induce CHGB aggregation in both

16 membrane-bound and soluble states (Fig. 3).

18 The CHGB anion channel serves an important role in normal granule maturation. Without its $\mathrm{N}-$

19 terminal sorting signal, the rest of CHGB might still form a channel, but would be mis-delivered.

20 CHGB likely uses a strong sorting signal for proper delivery of the channel-forming portion. The

$21 \mathrm{CLC} 3 \mathrm{Cl}^{-} / \mathrm{H}^{+}$exchanger, very probably being absent from insulin-secretory granules 112 and

22 contributing little anion flux due to its tiny conductance and strict outward rectification

23 [comparing Fig. 2B with the data by 113, 114], functions differently in other intracellular 
compartments. However, even without residing in membranes of secretory granules, CLC-3 in cell surface or in endosomal membranes might still affect proton-pumping or chloride flux via physical interactions and facilitate $\mathrm{Ca}^{2+}$ influx via charge balance, which could explain its permissive role for granule release as observed in Clc3-null mice ${ }^{115,116 . ~ B e c a u s e ~ C H G B ~ a n d ~}$ CLC-3 are important for granule maturation and granule release, respectively, both $\mathrm{Clc}^{-/-}$and $\mathrm{Chgh}^{-/}$mice exhibited hyperproinsulinemia and lower catecholamine content in secretory

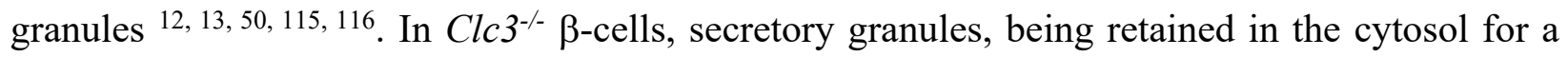
much longer time, might fuse with lysosomes or endo-lysosomes that could not be properly acidified without CLC-3 and become partially deacidified ${ }^{7,115,117-120}$. Further experiments could be performed to test this LRO-based mechanism.

CHGB may directly interact with $\mathrm{IP}_{3} \mathrm{Rs}$ and regulate $\mathrm{Ca}^{2+}$ release from the granules and in turn calcium-dependent exocytosis ${ }^{35,121,122}$. The soluble CHGB may interact with $\mathrm{IP}_{3}$ Rs from granular interior and regulate $\mathrm{Ca}^{2+}$ release ${ }^{123,124}$. Further studies are needed to understand the proposed gating effects of $\mathrm{CHGB}$ on $\mathrm{IP}_{3} \mathrm{Rs}_{\text {before granule exocytosis. }}$

With its single channel conductance orders of magnitude higher than that of CLC-3 or -5 , CHGB channels retained on cell surface become the dominating $\mathrm{Cl}^{-}$conductance during endocytosis of granular puncta (Fig. 1A) ${ }^{42}$. Recent high-resolution structures of CLC channels made it quite certain that CLC-3 is a transporter, not a channel ${ }^{115,125-145}$. CLC-3 was observed in early and late endosomes and synaptic vesicles ${ }^{113}$ whereas CLC-5 was detected in endocytic vesicles, especially in kidney proximal tubules ${ }^{146}$. After CHGB on the cell surface is endocytosed, its anion channel function would co-exist with CLC-3 or CLC-5 in endosomes and may be 
1 suppressed inside the endocytic compartments. There is hence a site where the secretory granules

2 and the endosomes may interact with each other. Whether CHGB functions as anion channels in

3 the endosomes or during its recycling to Golgi membranes, LROs or secretory granules remains

4 an open question.

6 Relations between CHGB and other proposed granular ion channels

8 Besides $\mathrm{IP}_{3} \mathrm{Rs}$, there are at least three distinct views on ion channels in secretory granules. First, 9 a large-conductance $\mathrm{Ca}^{2+}$-activated $\mathrm{K}^{+}$-channel $(\mathrm{BK})$, a few other $\mathrm{K}^{+}$channels and a $250 \mathrm{pS} \mathrm{Cl}^{-}$ 10 channel $\left(450 / 150 \mathrm{mM} \mathrm{Cl}^{-}\right)$were reported in isolated chromaffin granules ${ }^{34}$. Second, no 11 significant permeability of $\mathrm{K}^{+}, \mathrm{Na}^{+}, \mathrm{Mg}^{2+}$ or $\mathrm{Ca}^{2+}$ in chromaffin granules was observed four 12 decades ago 26, 27. These two views are at odds with each other, but could be reconciled in

13 consideration of low detection sensitivity of the flux assays performed in the earlier study ${ }^{27}$ or 14 possible contamination of the isolated chromaffin granules used in the more recent work ${ }^{34}$. Our 15 whole-cell recordings from PC-12 cells (Fig. 2A) detected mainly anion currents, suggesting that 16 in secretory granules the anion channels are probably much more abundant than the proposed $\mathrm{K}^{+}$ 17 channels, if any. The $250 \mathrm{pS} \mathrm{Cl}^{-}$channel might represent the $\mathrm{CHGB}$ channel as its conductance 18 could double from $\sim 125 \mathrm{pS}$ when $[\mathrm{KCl}]$ is increased from 150 to $450 \mathrm{mM}$, which awaits 19 verification using specific inhibitors or genetic manipulation.

21 Third, Kir6.1, ATP-sensitive $\mathrm{K}^{+} / \mathrm{Cl}^{-}$channels and $\mathrm{CLC}-1 / 2$ channels were reported from 22 zymogen granules, but the recorded $\mathrm{Cl}^{-}$channels showed properties completely different from 23 the same channels recorded from cell surfaces $37,38,114$. These conflicting results might have 
1 stemmed from experimental difficulties in achieving high purity of zymogen granules with no

2 contamination from other cellular membranes. In contrast, our genetic manipulations had higher

3 specificity and thus avoided technical limitations of previous studies. We detected anion

4 channels from released granules (Fig. 2) and probed specifically the physiological roles of native

5 CHGB channels in granule maturation and acidification (Figs. 4-6). Our findings set a stage for

6 future studies of the proposed relations between CHGB and other ion channels in regulated 7 secretion.

8

9

10

11

12 Our data from six different angles collectively support the main conclusion that native CHGB

13 proteins in bovine, rat and mouse neuroendocrine cells all form a chloride channel inside

14 secretory granules and on cell membranes, and this channel function is necessary for normal

15 granule acidification and cargo maturation in neuroendocrine cells. The well-conserved CHGB

16 proteins from zebra fish to human constitute a new family of intracellular anion channels that

17 serve the $\mathrm{Cl}^{-}$shunt pathway proposed more than four decades ago and are essential to normal

18 acidification of intracellular compartments related to regulated secretion and probably the

19 recycling of the granular components in various types of CHGB-expressing cells. Potential

20 CHGB functions in ER and Golgi apparatus, budding of nascent granules and homotypic fusion

21 of ISGs as well as the resorting of ISG contents remain open for future studies. 
1 METHODS: (Details available in Supplemental Information)

2 1. Molecular cloning of CHGB and its different mutants in pFastbac 1

3 2. Knockdown of $\mathrm{CHGB}$ in neuroendocrine cells and rescue by overexpressing CHGB or

4 CHGB $\triangle \mathrm{MIF}$

5 3. Detection of insulin and proinsulin in INS-1 cells

6 4. Western blotting of vesicular ATPase subunit A2 (ATP6V0A2)

7 5. ELISA assay for detecting dopamine released from PC-12 cells

8 6. $\mathrm{pH}$ measurements in intracellular acidic compartments using DND-160

9 7. Isolation of pancreatic islets from wild-type and CHGB-knockout mice

10 8. Purification of native bCHGB from bovine pancreas

11 9. Electrophysiological recordings from PC12 cells before and after depolarization-induced $\mathrm{Ca}^{2+}-$

12 dependent release of secretory granules.

13 10. High-pressure freezing and immuno-Electron Microscopy (HPF immuno-EM)

14 11. Quantitative analysis of HPF immuno-EM data

15 12. Preparation of monolayer cultures of pancreatic beta-cells.

16 13. In situ calibration of ratiometric $\mathrm{pH}$ measurement using NPY-ClopHensor

17 14. Fluorescence imaging and analysis using NPY-ClopHensor 


\section{1 . Ethics approval and consent to participate}

2 The authors confirm that all experiments with mice were performed by following protocols

3 approved by the IACUC committee at UF.

\section{4 . Consent for publication}

$5 \quad$ All authors agree to publish this paper.

6 . Competing interests:

7 The authors declare no conflict of interest.

\section{8 . Availability of data and materials}

9 All raw data are available upon request. We will share the constructs and the information of the

10 animal model with those who will make requests.

\section{1 . Author Contributions:}

12 Q.-X.J. designed and oversaw the experimental studies, analyzed the results with all co-authors.

13 G.Y. designed and performed all the molecular biology, biochemistry and cell-based experiments

14 and analyzed acquired data. H.W., Q.W. and M.X.Z. conducted the electrophysiological

15 experiments in PC-12 cells and analyzed data together with Q.-X.J. M.A. and G.Y. performed

16 the dissection of mice and isolation of pancreatic islets with C. M's advice. W.H and E.A.P

17 provided advice and assistance in preparation of monolayers of pancreatic beta-cells. J.O., S.C.

18 and P.V. did HPF-immuno-EM and data analysis. All authors contributed to data analysis and 19 manuscript writing.

20 . Funding and acknowledgements: Details are in the supplementary information. 
Figure legends:

2

Figure 1. Membrane association of native CHGB on cell surface and inside insulin-

4

5

(A) CHGB retention on cell surface after granule release. INS-1 cells were incubated with high $\mathrm{KCl}(55 \mathrm{mM})$ for $15 \mathrm{~min}$ at $37{ }^{\circ} \mathrm{C}$ to release granules before being labeled with anti-CHGB antibody on ice. An Alexa 488-conjugated secondary $\left(2^{\text {nd }}\right)$ antibody was used to visualize CHGB on cell surface by confocal FM. Upper row: images of control (CTL) cells treated only with $2^{\text {nd }}-$ $\mathrm{Ab}$; Middle row: images of cells labeled with anti-SOCS1 antibody and the $2^{\text {nd }}$-antibody; Lower row: images of cells labeled with anti-CHGB antibody and the $2^{\text {nd }}$-antibody. (B) Histogram of the number of CHGB puncta per cell within the confocal image planes (top surfaces of the cells) under different conditions (>50 cells) in (A). (C) Average number of puncta per cell on the top surfaces. ${ }^{* *}: p<0.001$ (D) HPF-immuno-EM images showing distribution of CHGB and insulin inside DCSGs of rat pancreatic $\beta$-cells. CHGB was marked by $12 \mathrm{~nm}$ gold particles while insulin by $6 \mathrm{~nm}$ ones. Individual granules were demarcated for quantitative analysis (middle and right panels). (E) Histogram of CHGB- and insulin-labeling nanogold particles in shortest distances from granular membranes. A good fraction of CHGB-labeling gold particles are in close proximity to the granular membrane as compared to the insulin-labeling ones, which distributes more evenly in DCSGs. 


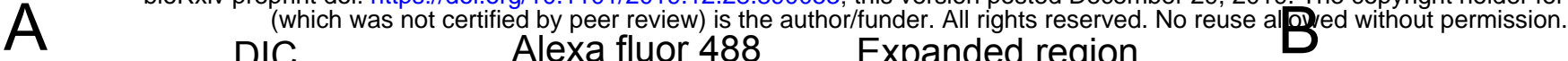
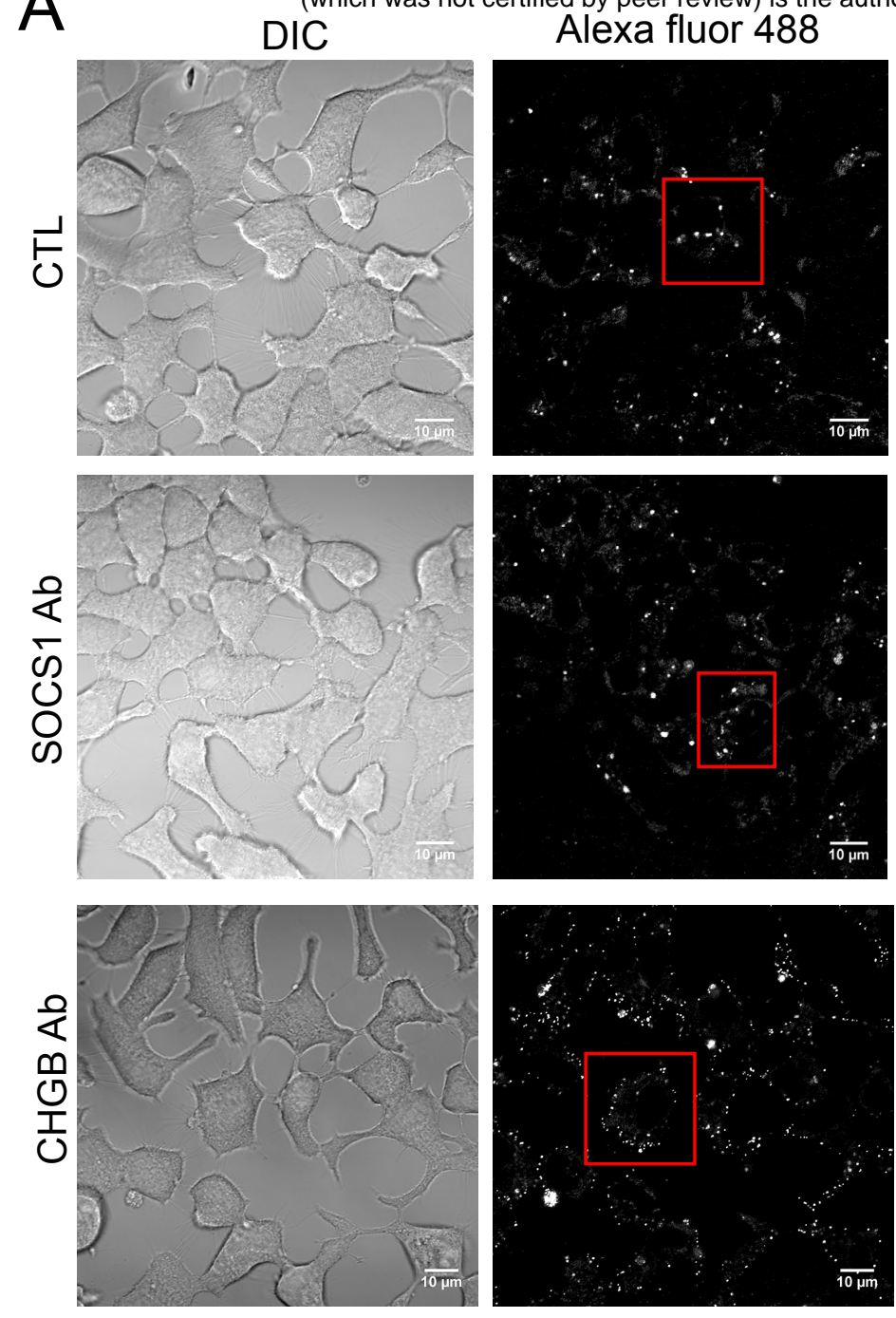

Expanded region
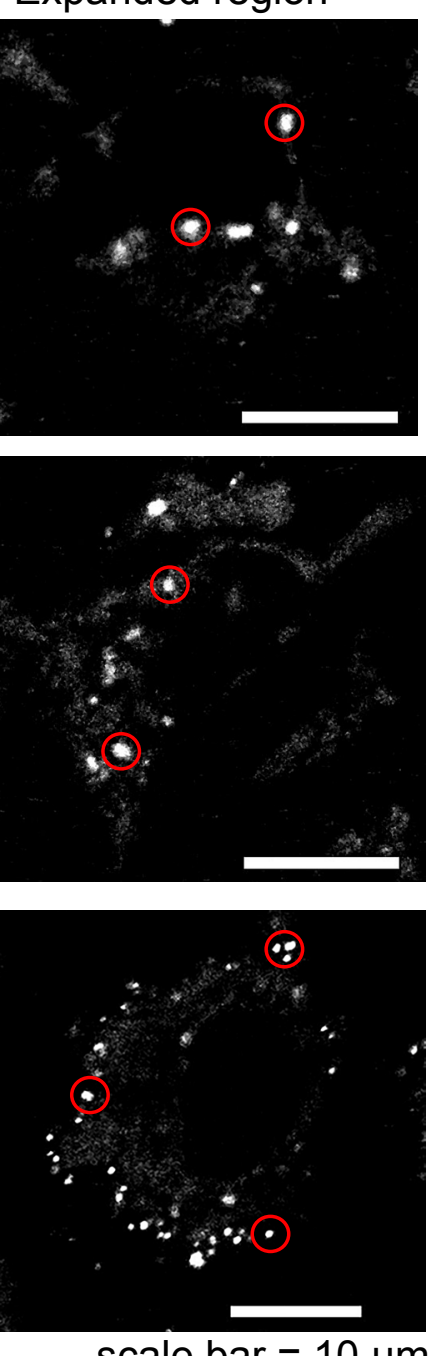

scale bar $=10 \mu \mathrm{m}$

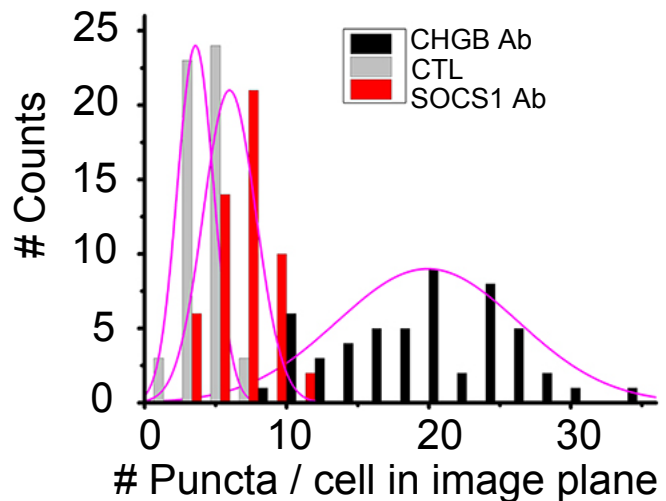

C

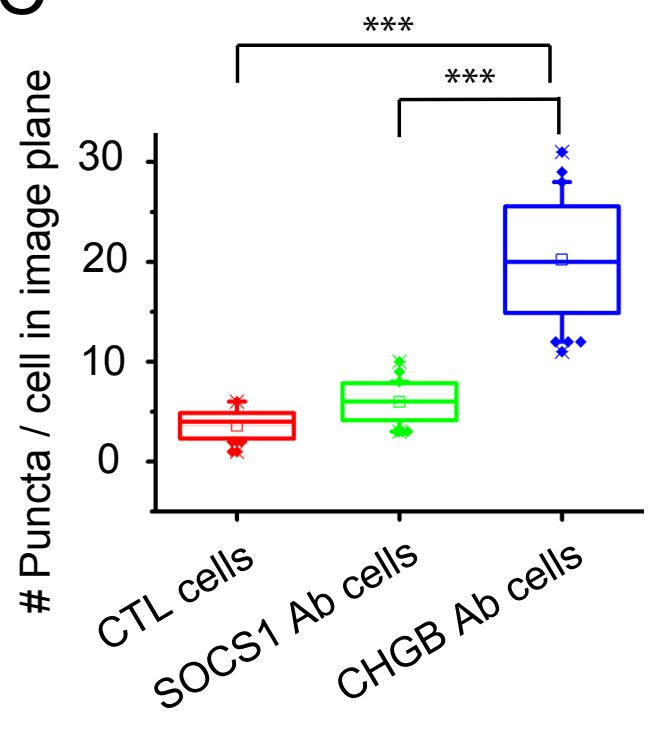

D

Granular localization of chromogranin B (CHGB) and insulin
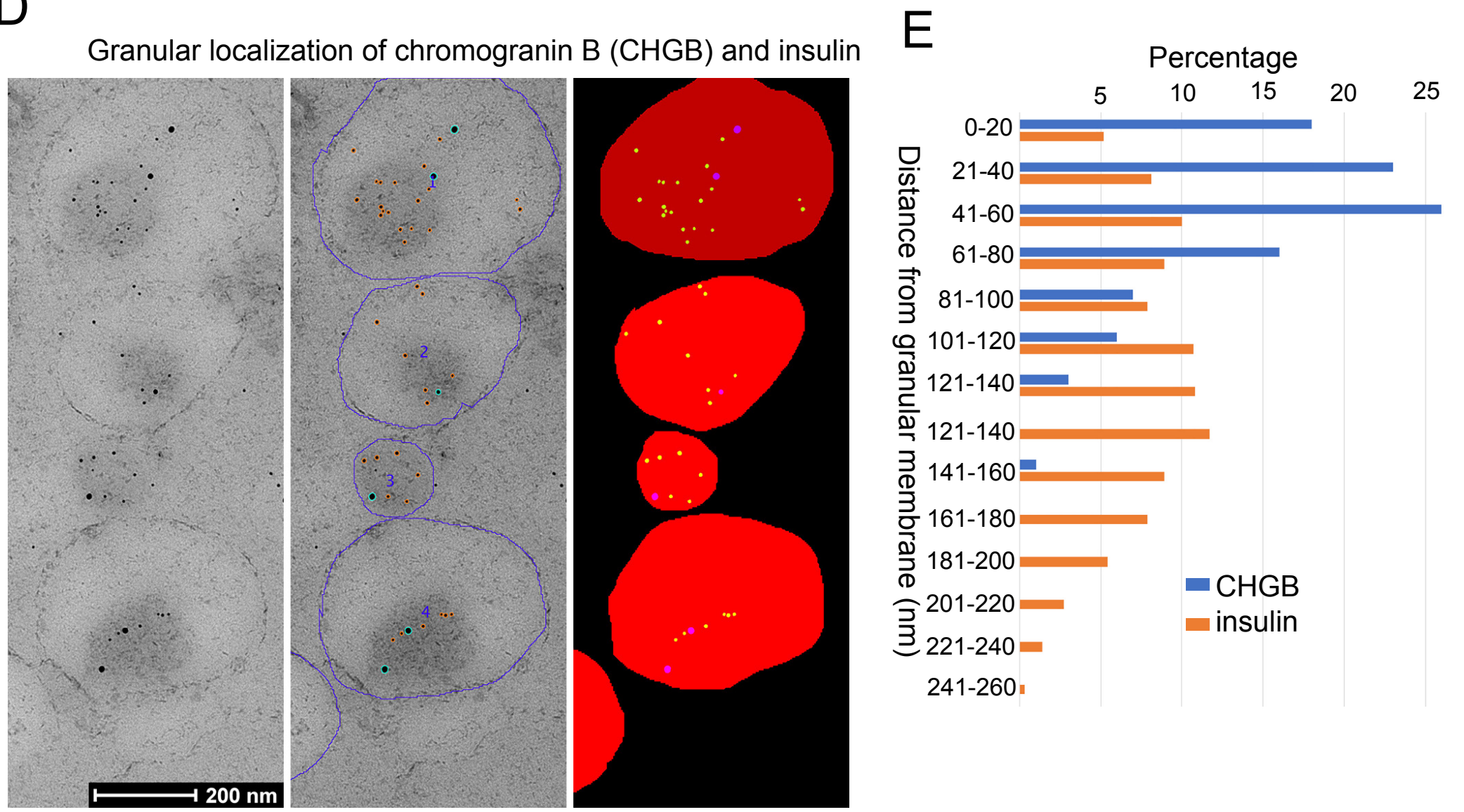

$12 \mathrm{~nm}$ gold particles: chromogranin $\mathrm{B} ; 6.0 \mathrm{~nm}$ gold particles : insulin 
2 granule release in PC-12 cells. (A) Whole-cell recordings from a PC-12 cell (top bars; out of more than 10 cells) that was initially perfused with a $\mathrm{Ca}^{2+}$-free solution and then with a normal bath containing $2.5 \mathrm{mM} \mathrm{Ca}^{2+}$. Pipette electrode contained low $\mathrm{Cl}^{-}$. Holding potential was -80 $\mathrm{mV}$. Every second, a voltage protocol made of a ramp (-80 to $+80 \mathrm{mV}$ in $100 \mathrm{~ms})$, a step (50 ms at $80 \mathrm{mV}$ ) and another step $(400-\mathrm{ms}$ at $0 \mathrm{mV}$ ) was delivered. Whole-cell currents were stable in $\mathrm{Ca}^{2+}$-free bath (first period including time point $a$ ) and increased gradually in the normal bath. Switching the bath to a $\mathrm{Cl}^{-}$-free solution abolished the increased outward current. After 5 minutes, the outward current $(+80 \mathrm{mV})$ became saturated (fourth period including time point $b$ ), which was almost completely abolished after removal of extracellular $\mathrm{Cl}^{-}$(fifth period including time point $c$ ). The inward current at $-80 \mathrm{mV}$ showed a much smaller $\mathrm{Ca}^{2+}$-dependent increase and was only slightly sensitive to extracellular $\mathrm{Cl}^{-}$-free solution. (B) Typical current traces elicited by ramp pulses at time points $a, b$, and $c$. The trace at time point $b$ showed a reversal potential of $\sim$ $40 \mathrm{mV}$ and weak outward rectification. Traces at time points $a$ and $c$ had a reversal potential of $0 \mathrm{mV}$ and almost no rectification. (C) Average current change rate (mean $\pm \mathrm{SEM}$ ) at $+80 \mathrm{mV}$, expressed as $\mathrm{pA} / \mathrm{sec}$, for cells in $\mathrm{Ca}^{2+}$-free $(\mathrm{n}=5)$ and $2.5 \mathrm{mM} \mathrm{Ca}^{2+}(\mathrm{n}=14)$ solutions. ${ }^{* *}: p<$ 0.05 by Student's $t$ test. (D) Time course of current development at $+80 \mathrm{mV}$ for cells transfected with scrambled (control; open circles) and CHGB-targeting siRNAs (siRNA; solid circles). Pipette solution contained NMDG-Cl. Cells were held at $0 \mathrm{mV}$. Voltage ramps from -80 to +80 $\mathrm{mV}$ in $500 \mathrm{~ms}$ with a $50-\mathrm{ms}$ step at $-80 \mathrm{mV}$ before and a $50-\mathrm{ms}$ step at $+80 \mathrm{~ms}$ after the ramp, were applied every 2 sec. Cells were placed in $\mathrm{Ca}^{2+}$-free bath first and then in a normal bath with 
1 CHGB siRNA-transfected cells. (E) Comparison of changes in average current density over 1.5

2 minutes for the same groups of cells showed in (D). ***: $\mathrm{p}<0.005$. 
A

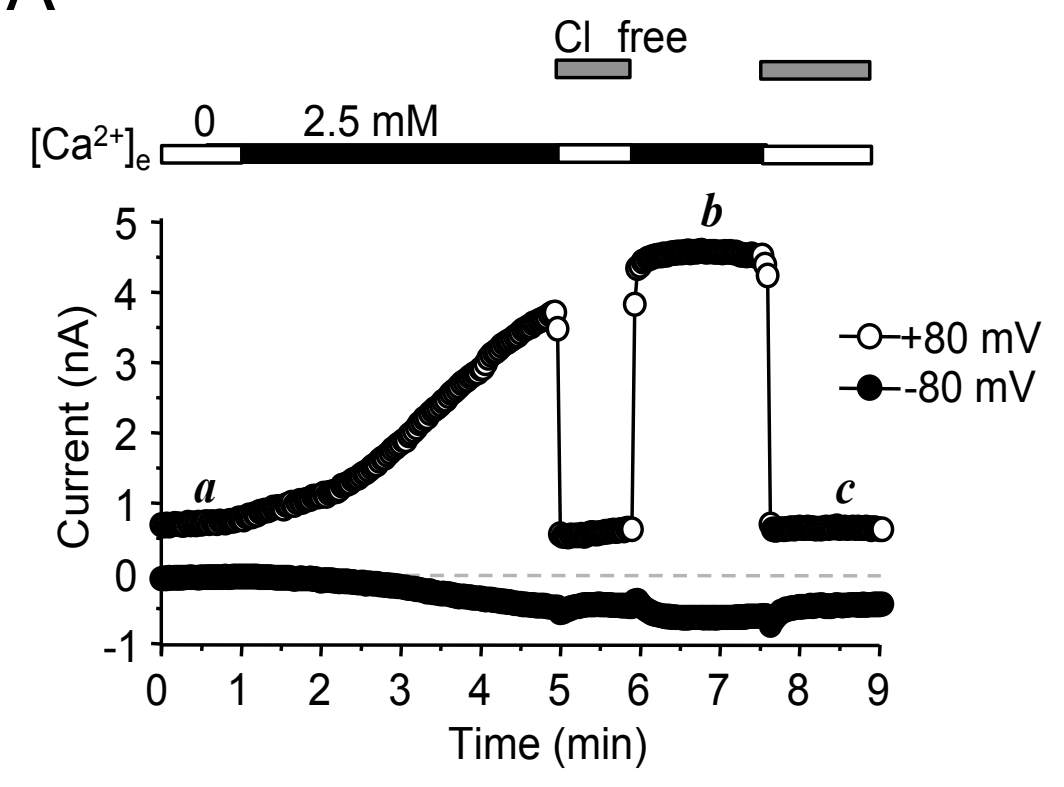

B

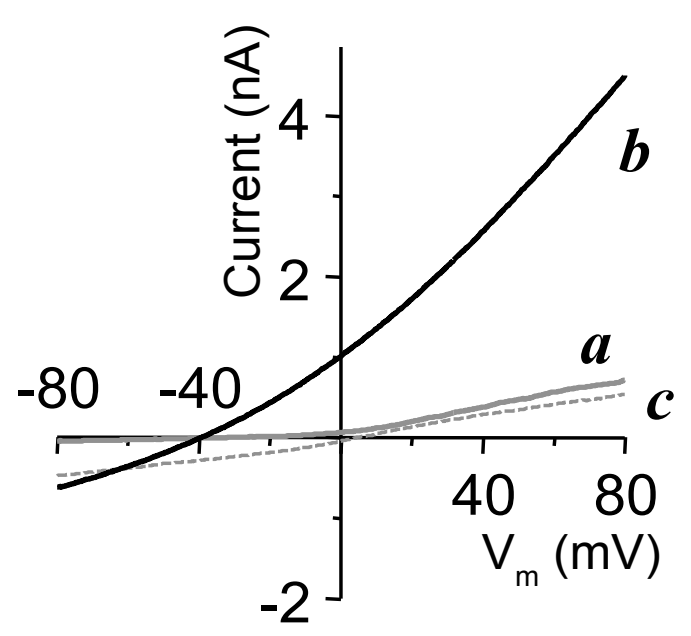

C

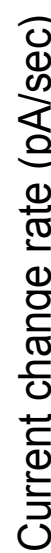

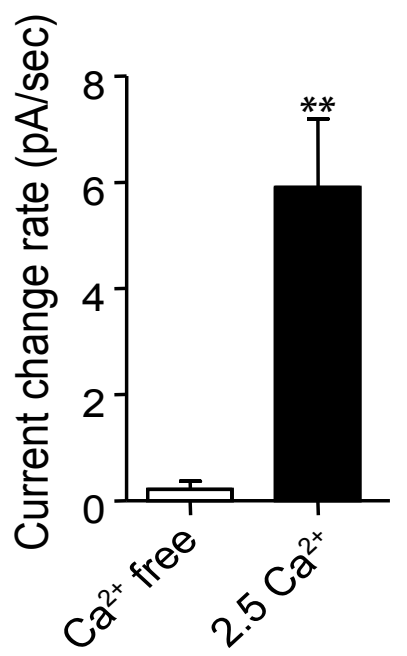

D
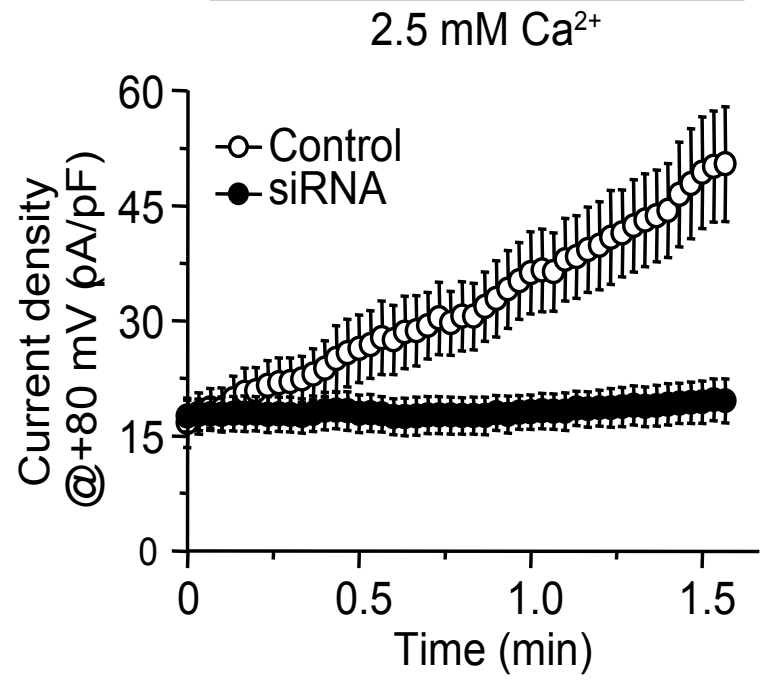

$E$

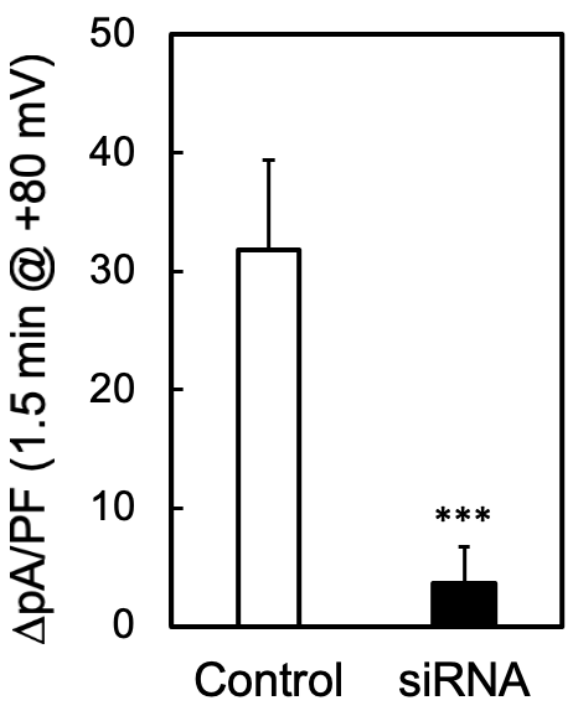


1 Figure 3. Membrane-bound and soluble bovine $\mathrm{CHGB}$ proteins both reconstitute $\mathrm{Cl}^{-}$ channels in membrane.

(A) Purified bCHGB in detergents from membrane-bound fractions of bovine pancreatic granules. bCHGB peak fractions eluted out of a Superdex 200 were assayed by SDS-PAGE and Coomassie blue staining. (B) Western-blot of bCHGB from the three fractions in (A). (C) Quantification of bCHGB and two contaminating bands in lane 2 of (A). (D) Light-scatteringbased flux assay of purified membrane-bound bCHGB reconstituted in vesicles loaded with 300 $\mathrm{mM} \mathrm{KCl}$. Vesicles were first exchanged into an external solution containing $300 \mathrm{mM} \mathrm{KI}$ and varying amount of $\mathrm{KCl}$. Valinomycin-triggered change in light-scattering was recorded. DMSO was used as control. (E) Inhibition of $\mathrm{Cl}^{-}$efflux by extravesicular $\mathrm{Cl}^{-}$. Data from (D) (black circles; error bars are s.d., $\mathrm{n}=3$ ) fitted with a Hill-equation (black line) yielded an apparent $k_{D}$ of $\sim 0.47 \mathrm{mM}$ and a Hill coefficient of 1.0. (F\&G) Inhibition of $\mathrm{Cl}^{-}$efflux by DIDS. Fitting of the flux data points from (F) (black circles; error bars: $s . d$. $\mathrm{n}=3$ ) with a Hill-equation yielded a $k_{D}$ of $\sim 0.43 \mu \mathrm{M}$ and a Hill coefficient of $\sim 1.0$. (H) bCHGB in soluble fractions released from pancreatic granules were eluted from a Superose S6 column. Its three peak fractions were assayed by Coomassie blue-stained SDS-PAGE. The first two fractions contain similar bands as those in (A). The third fraction has a clear degradation band at $\sim 50 \mathrm{kDa}$. (I) Western blot of bCHGB separated as in (H). CHGB proteins in soluble fractions exhibited more degradation than those in membrane-associated fractions (B). (J) $\underline{\text { Top: }}$ bCHGB purified from soluble fractions reconstituted in vesicles made of DOPC: sphingomyelin: cholesterol. Vesicles were floated from bottom to top in a Ficoll 400 density gradient (5\%,10\% and 15\%). Gradient fractions were assayed by SDS-PAGE and Coomassie blue staining. Full-length bCHGB is marked. More degradation was observed after reconstitution. Bottom: Full-length bCHGB bands in individual 
1 lanes of the top gel were quantified and normalized against total full-length bCHGB in all

2 fractions, and plotted to show the relative distribution of CHGB among different fractions (blue)

3 For comparison, similar analysis of bCHGB purified from membrane-bound fractions in (A)

4 were conducted and plotted in orange. Soluble fractions showed more degradation, and was more

5 poorly reconstituted than membrane-bound ones. (K) bCHGB from soluble (blue) and

6 membrane-associated (red) fractions were compared in the light-scattering-based assay for $\mathrm{Cl}^{-}$

7 flux. The control vesicles had no protein and showed no signal (green). Inset: Relative activity in

8 the ion-flux assays from the two different forms of native bCHGB was compared quantitatively. 
1 Figure 4. Native CHGB channel is critical for normal granule acidification and insulin

\section{maturation in INS-1 cells}

(A) Ratiometric pH measurements. INS-1 cells in a glass-bottomed dish (DIC) were transfected with control (CTL; top row) or CHGB siRNAs (rows 2 to 4). In top two rows, cells were stained after 96 hours with one medium change at 48th hour. In rows $3 \& 4$, 48 hours after transfection with CHGB siRNAs, cells were transfected to express CHGB or CHGB $\triangle$ MIF and were imaged after 48 more hours. Excitation: $410 \mathrm{~nm}$; emission: $485 \mathrm{~nm} \& 510 \mathrm{~nm}$. A small area (red window) in each $510 \mathrm{~nm}$ image was expanded to show granules. Measurement at 510-nm in row 4 was weaker due to $\mathrm{pH}$ difference. (B) Histogram of intragranular $\mathrm{pH}$ values from individual cells treated with CTL or CHGB siRNAs (black vs. red). (C) Histogram of intragranular pH values from cells whose endogenous CHGB were suppressed by siRNA before transient overexpression of wild-type CHGB or CHGB $\Delta \mathrm{MIF}$ (green vs. blue bars). (D) Average number of granules per INS-1 cell in the confocal image plane under different conditions in (A). (E) Average $\mathrm{pH}$ values of secretory granules $(\mathrm{n}>110)$ from cells as in $(\mathbf{A}-\mathbf{C})$. (F) Western blot of ATP6V0A2 (vesicular $\mathrm{H}^{+}$-ATPases) from cells treated as in (A). (G) Western blot of insulin and proinsulin from lysates of cells treated as in (A). (H) Relative total insulin (insulin + proinsulin; upper panel) and insulin maturation (Ins / ProIns; lower panel) from cells treated as in (A). Relative total insulin was normalized to cells treated with CTL siRNAs (black). Error bars are s.d. in (D) (n > 100) and (G) (n=3). **: $p<0.05 ; * * *: p<0.001 ; * * * *: p<0.0001$; ns: not significant. 
A bioRxiv preprint doi: https://doi.org/10.1101/2019.12.28.890053; this version posted December 29, 2019. The copyright holder for this preprint
(which was not certified by peer review) is the author/funder. All rights reserved. No reuspllowed without permission.

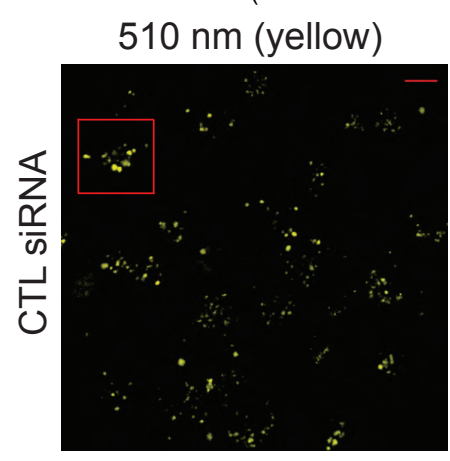

Expanded
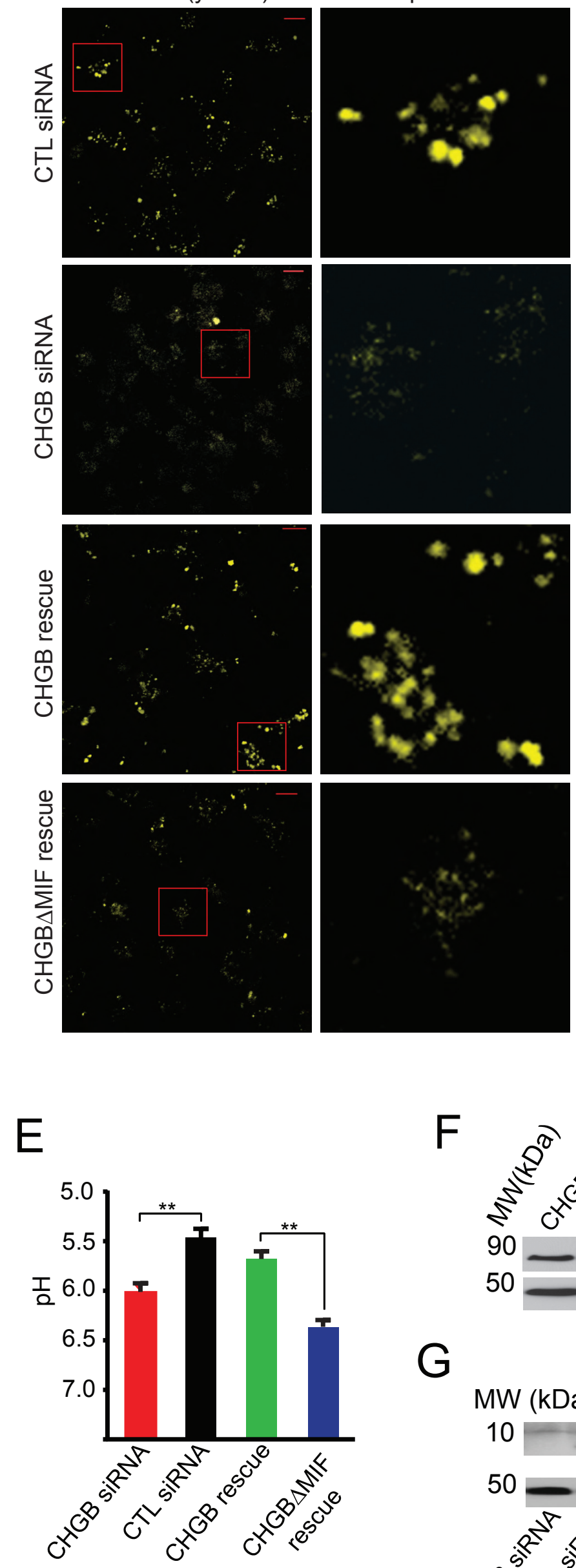

Scale bars $=10 \mu \mathrm{m}$

$485 \mathrm{~nm}$ (blue)
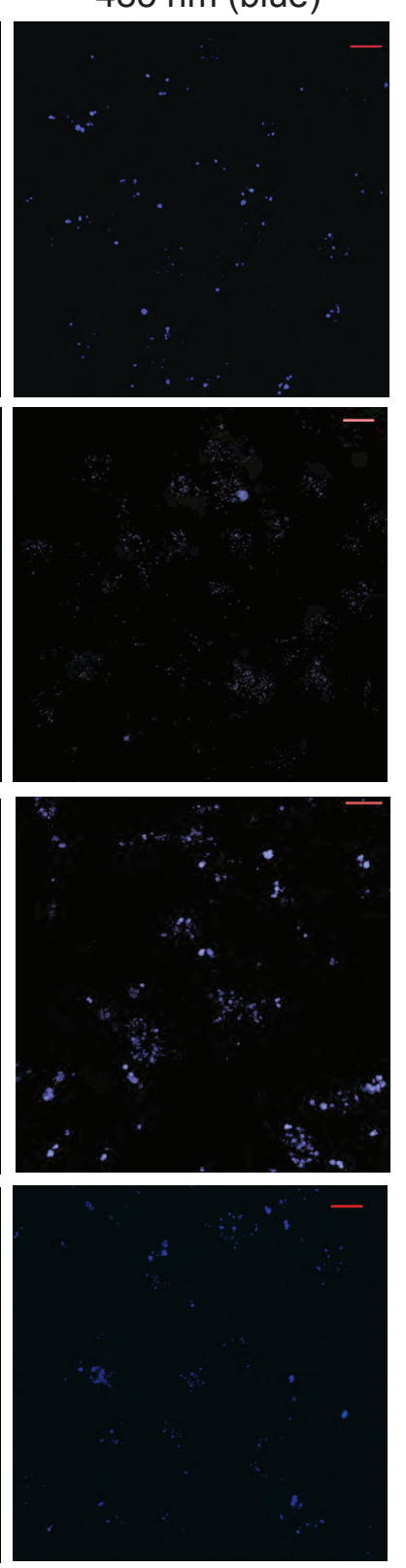

Scale bars $=10 \mu \mathrm{m}$

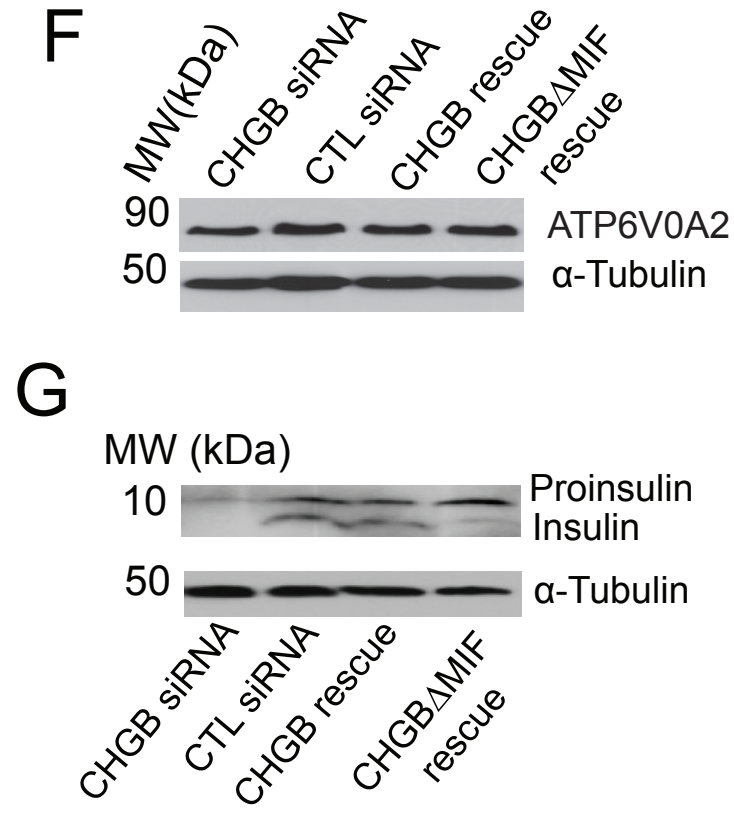

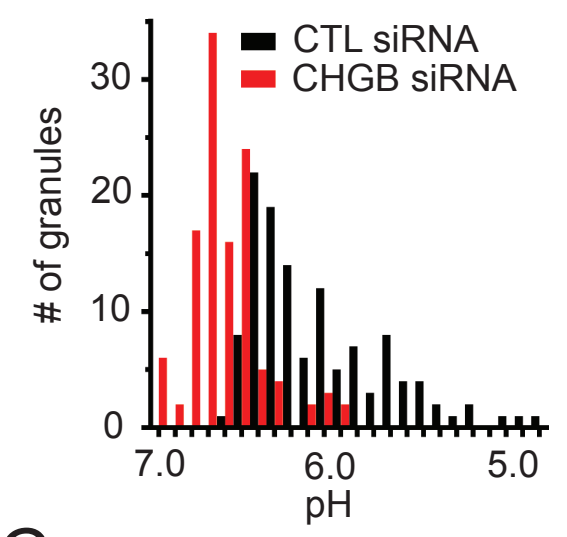

C
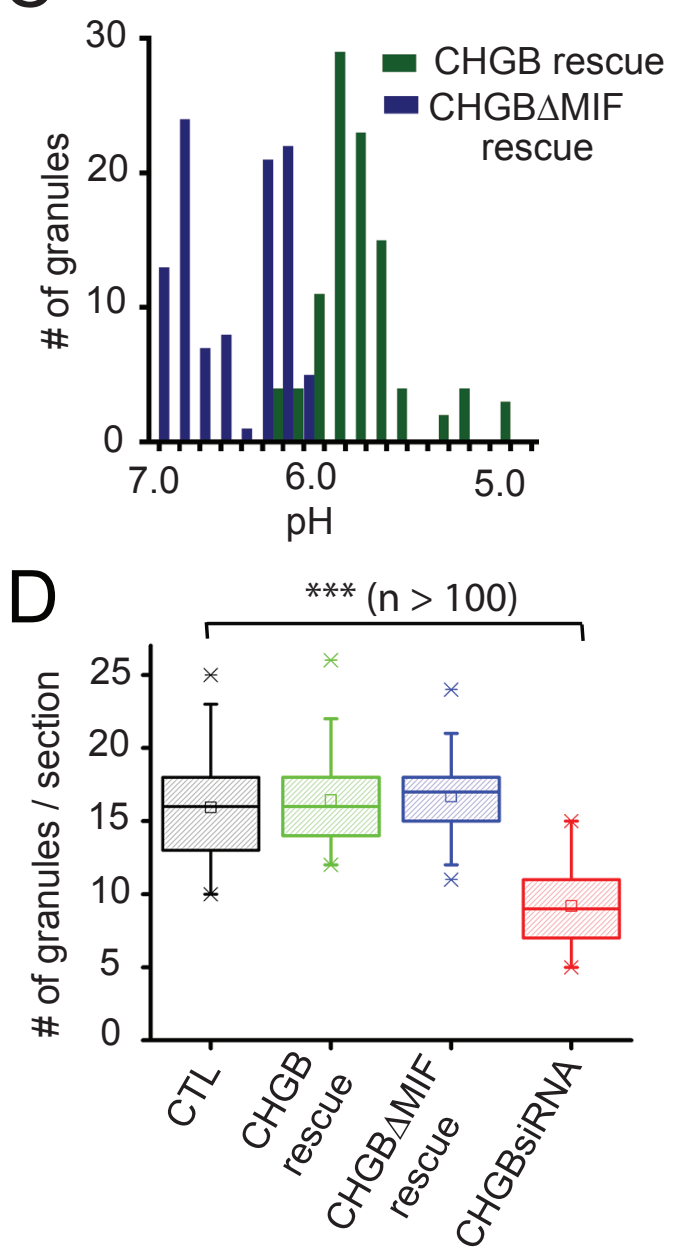

$\mathrm{H}$
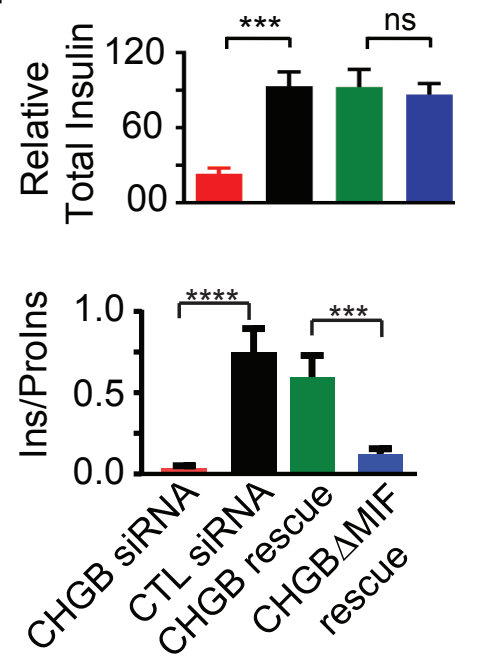


\section{Figure 5. CHGB channel function is critical for granule acidification and dopamine loading}

2 in PC-12 cells. (A) Ratiometric pH measurements. PC-12 cells were transfected with control

3 (black) or CHGB siRNAs (red); after 48 hours some of the CHGB knockdown cells were transfected to overexpress CHGB (greed) or CHGB $\triangle$ MIF (purple). After 96 hours, cells were treated with DND-160 for ratiometric imaging. Typical images are showed in supplementary

6 figure S7. Average granular $\mathrm{pH}$ values from hundreds of granules are shown in a bar graph.

7 Average intragranular $\mathrm{pH}$ from granules in PC12 cells without siRNA treatment is in grey. (B)

8 Histogram of intragranular $\mathrm{pH}$ of PC-12 cells transfected with control (black), and CHGB (red)

9 siRNAs. (C) Histogram of intragranular $\mathrm{pH}$ values of CHGB-knockdown PC-12 cells overexpressing wild-type CHGB (green) or CHGB $\triangle \mathrm{MIF}$ (blue). (D) Western blot of

11 ATP6V0A2 in four differentially treated PC-12 cells $(\mathbf{B \& C})$. The same number of cells were used for analysis. (E) Relative dopamine content in RRGs released from depolarization-treated cells. An ELISA kit was used. Standard $t$-test for (A) and two-tailed Welch's $t$-test for (E). ${ }^{* *}: p$ $<0.05$; ***: $p<0.001$. (F) Schematic drawing to show $\mathrm{H}^{+}$pumping and $\mathrm{Cl}^{-}$influx that drive granular acidification and $\mathrm{H}^{+}$-coupled transport of dopamine (or epinephrine) into secretory granules by vMAT. (G) CLC-3 or CLC-5 knockdown has negligible effect on intragranular $\mathrm{pH}$. INS-1 cells were transfected with control, CHGB, CLC-3 or CLC-5 siRNA. After 96 hours, cells were loaded with DND-160 for imaging. Average $\mathrm{pH}$ values were calculated from hundreds of stained granules, and were presented as a bar diagram. ${ }^{*}: p<0.05$. There was no significant change in average intragranular $\mathrm{pH}$ for cells treated with CLC-3 or CLC-5 siRNAs. (H) Western blot shows effective knockdown of CLC-3 in INS-1 cells using different concentrations of siRNAs. (I) Western blot showing no obvious cross-effect between the three different siRNAs. 
$\mathrm{pH}$ in PC-12 Cells

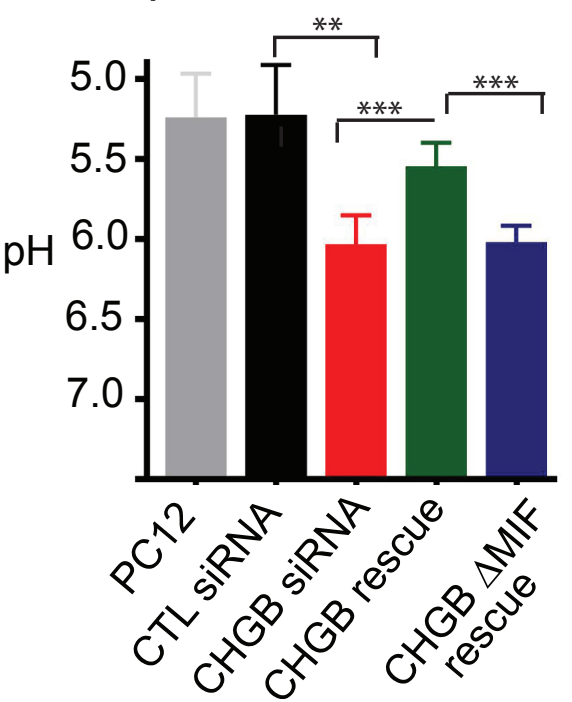

D

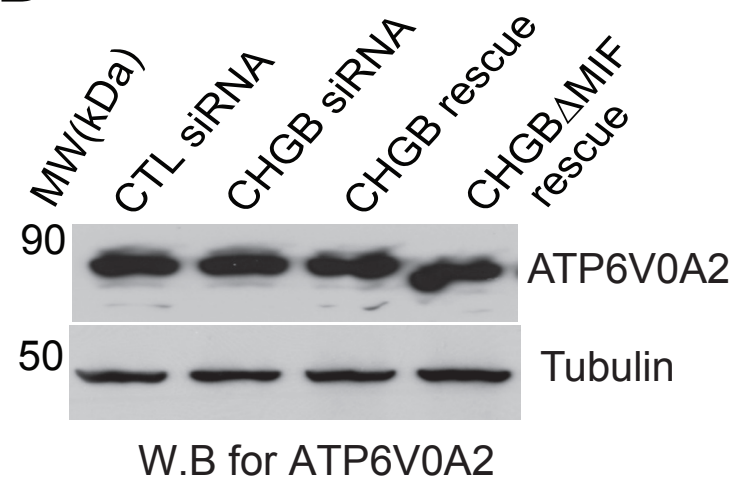

G

$\mathrm{pH}$ in INS-1 Cells

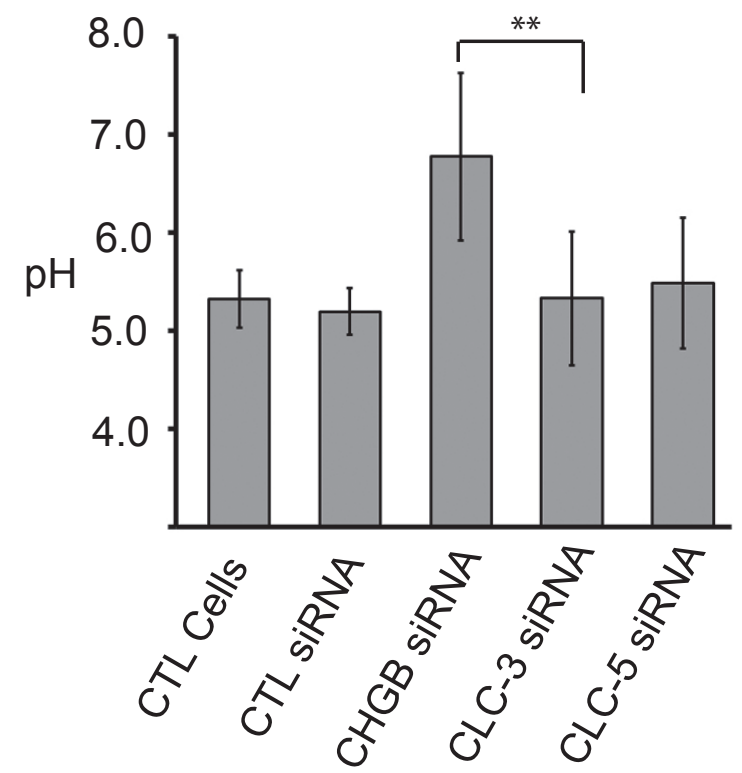

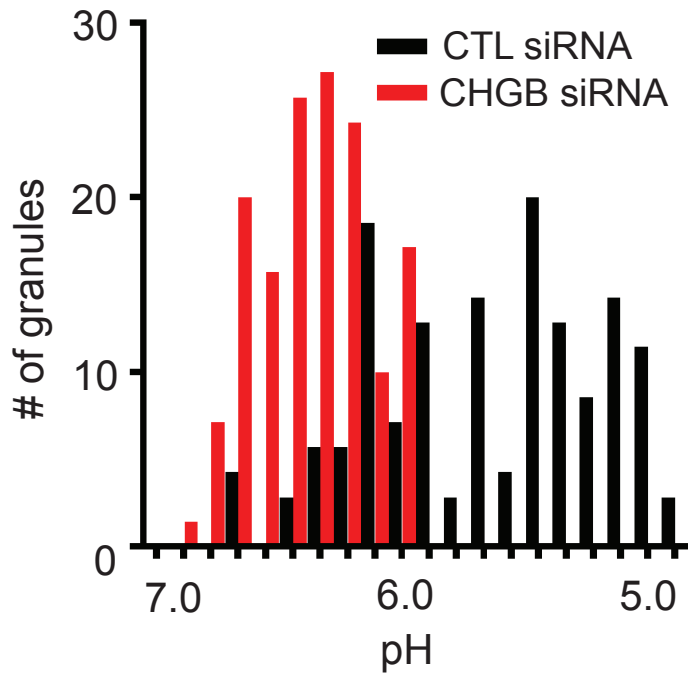

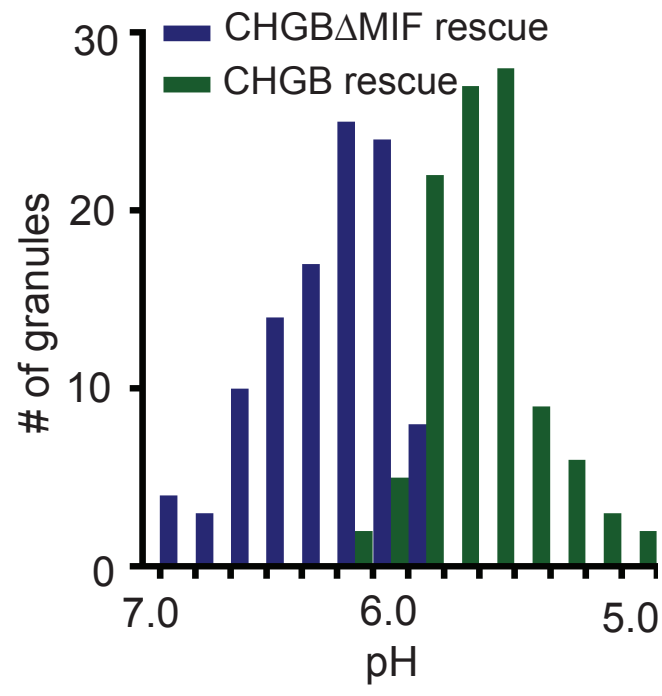

E
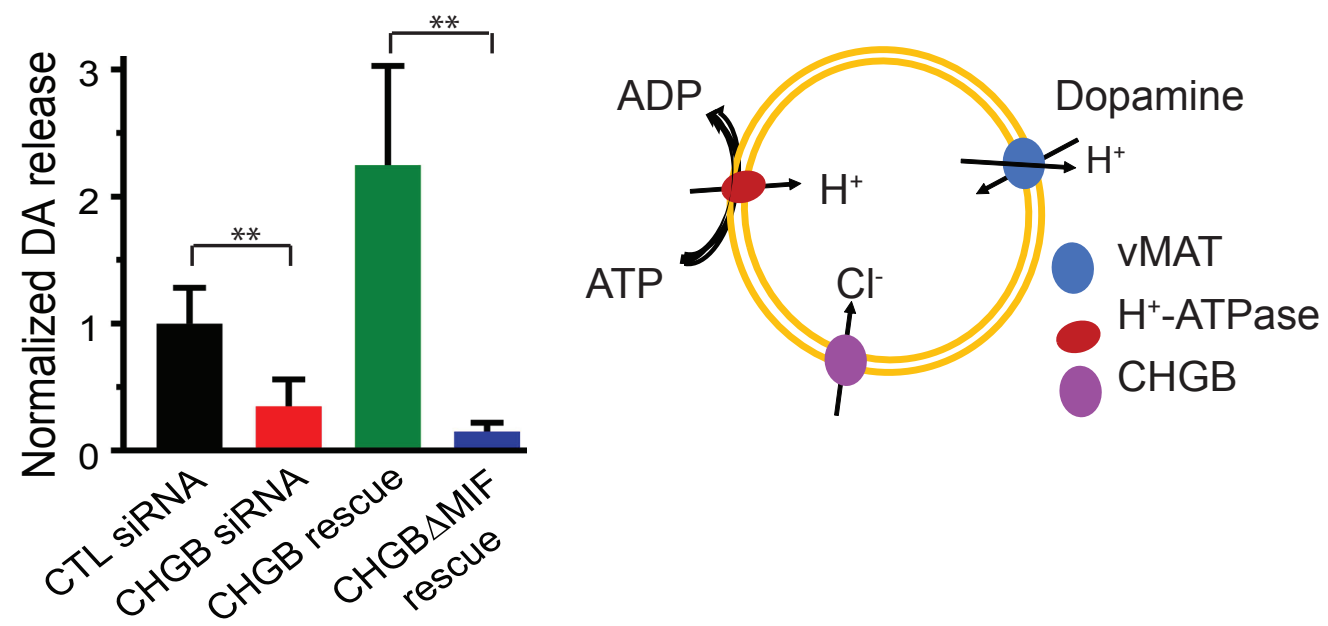

$\mathrm{H}$

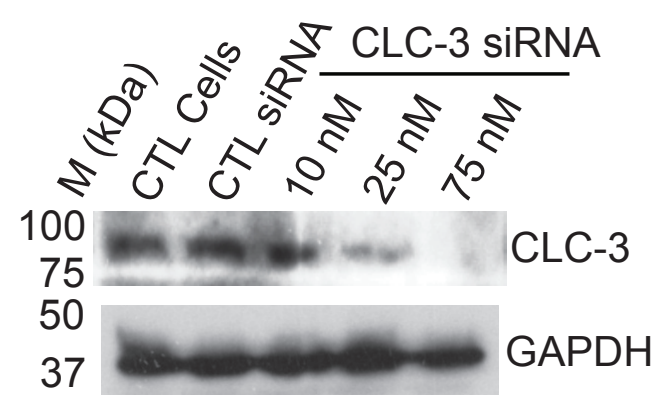

W.B for CLC-3 knockdown in INS-1 Cells

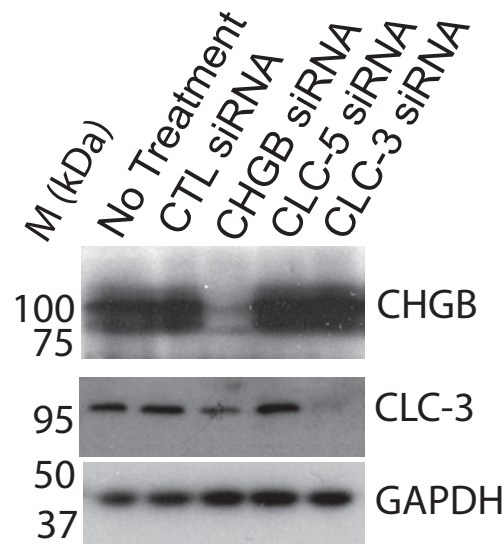

Effect of siRNA on CLC-3 in INS-1 cells 


\section{Figure 6. Murine CHGB supports normal granule acidification of insulin-secretory}

2 granules in primary pancreatic $\boldsymbol{\beta}$-cells. (A) Two typical pancreatic islets isolated from mice

3 (left) and western blotting of CHGB from liver tissues removed from a wild-type $\left(\mathrm{Chg}^{+/+}\right)$and a

4 CHGB-knockout $\left(\mathrm{Chgh}^{-/}\right)$mouse. (B) Typical ratiometric images of pancreatic $\beta$-cells in

5 individual islets from $C h g b^{+/+}$and $C h g b^{-/}$mice. Ten islets of each genotype were stained with

6 DND-160 and imaged under a Zeiss LSM-800 confocal microscope (63x objective). Excitation:

$7410 \mathrm{~nm}$; emission: $485 \mathrm{~nm}$ and $510 \mathrm{~nm}$. A small area (red window) in each $510 \mathrm{~nm}$ image was

8 expanded to show granules (yellow channel in the right column). $\beta$-cells from $C h g b^{-/}$mice have

9 fewer bright granules (above background) and fainter signals at $510 \mathrm{~nm}$ due to deacidification.

10 (C) Histograms of intragranular $\mathrm{pH}$ values measured from granules in isolated islets from both

11 male and female mice of different genotypes. All mice were littermates and were 9-weeks old at

12 the time of analysis. (D) Average $\mathrm{pH}$ values for four different groups of mice in (C). **: $p<$

130.05 ; ***: $p<0.001$. (E) Typical ratiometric images in monolayers of $\beta$-cells grown out of

14 pancreatic islets isolated from $\mathrm{Chgb}^{+/+}$and $\mathrm{Chgh}^{-/-}$mice. After $\sim 7$ days, monolayers of cells were

15 transfected with an NPY-ClopHensor-expressing plasmid, and after another 48-72 hours, were imaged under a Zeiss LSM-710 confocal microscope (63x oil objective). Excitation: $488 \mathrm{~nm}$

17 (green) and $458 \mathrm{~nm}$ (cyan); emission: $510 \mathrm{~nm}$. $\beta$-cells from $C h g b^{-/-}$mice have fewer granules than the wild-type cells. (F) Western blotting of CLC-3 and CHGB in pancreatic tissues from $\mathrm{Chgb}^{+/+}$and $\mathrm{Chgb}^{-/-}$mice. GAPDH was used as loading control. (G) Average intragranular $\mathrm{pH}$ 

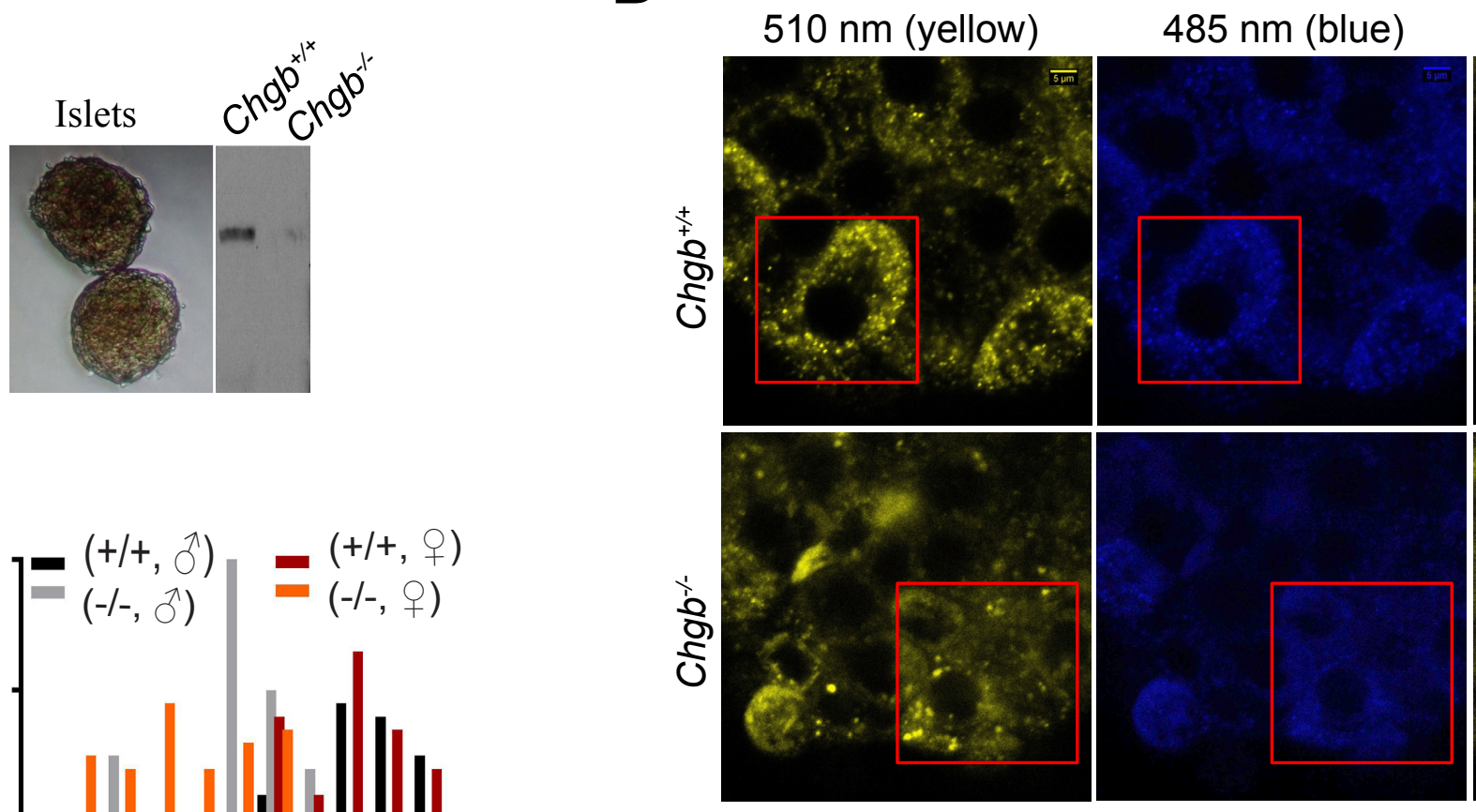
$510 \mathrm{~nm}$ (expanded)

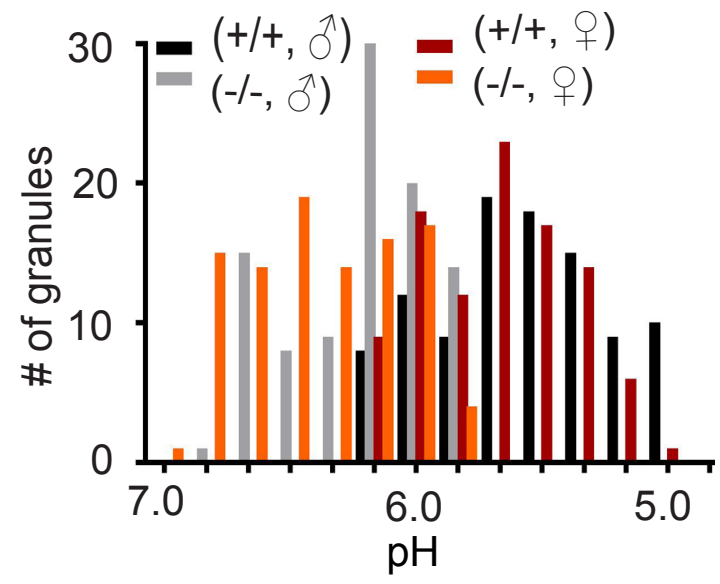

D
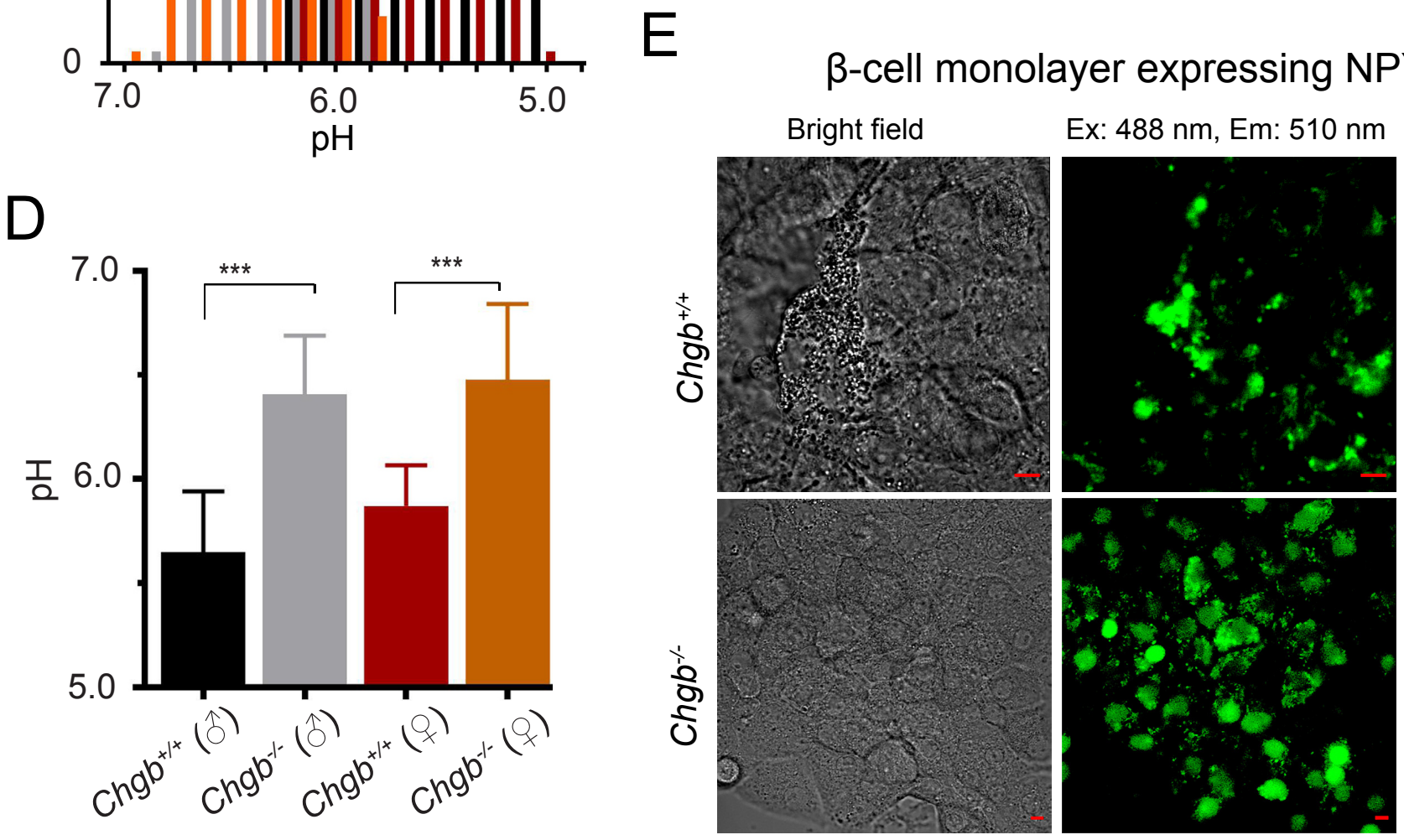
Ex: 488 nm, Em: $510 \mathrm{~nm}$

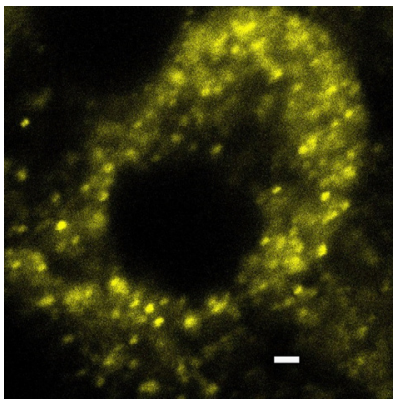

C

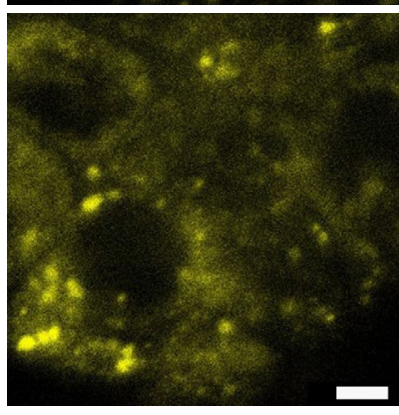

scale bar $=2.0 \mu \mathrm{m}$

\section{$\beta$-cell monolayer expressing NPY-ClopHensor}
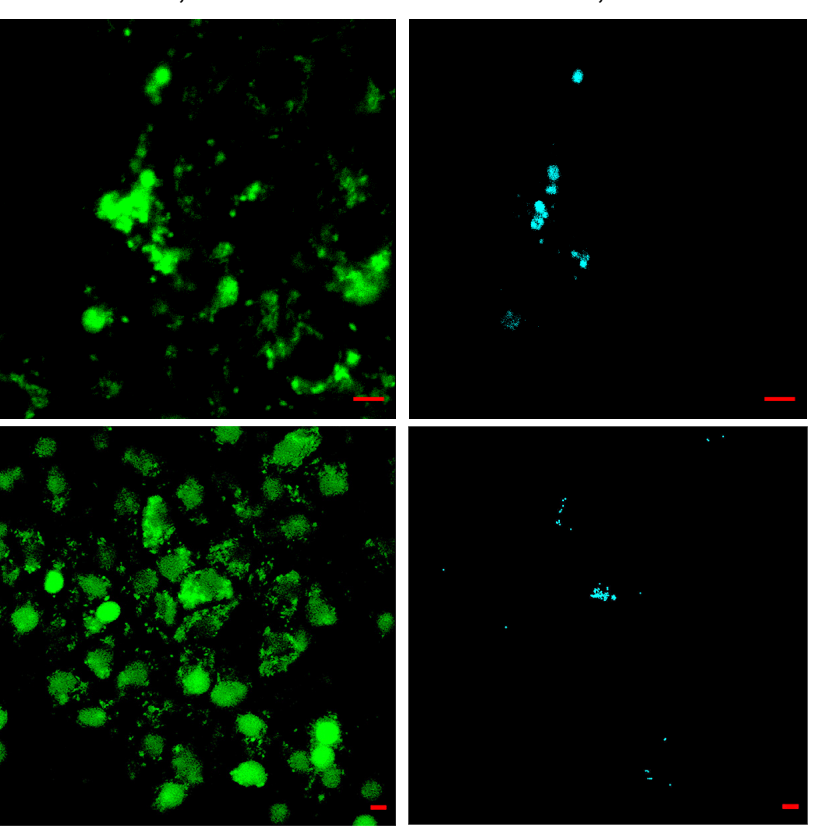

Scale bar $=5.0 \mu \mathrm{m}$

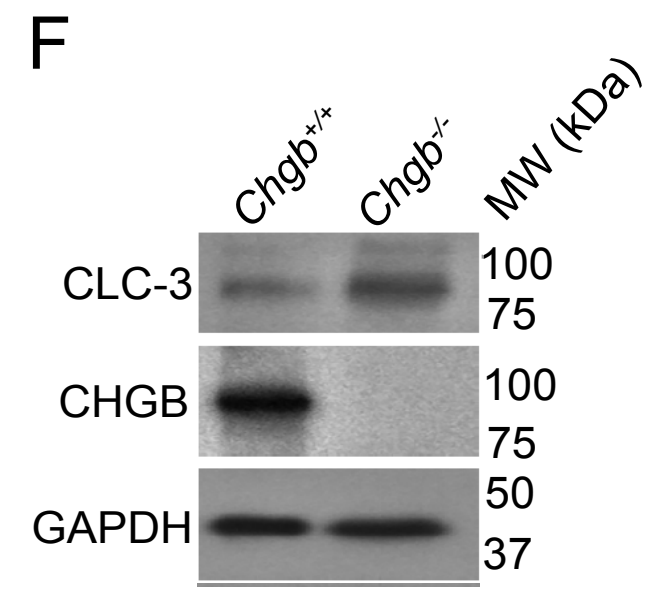

F
G

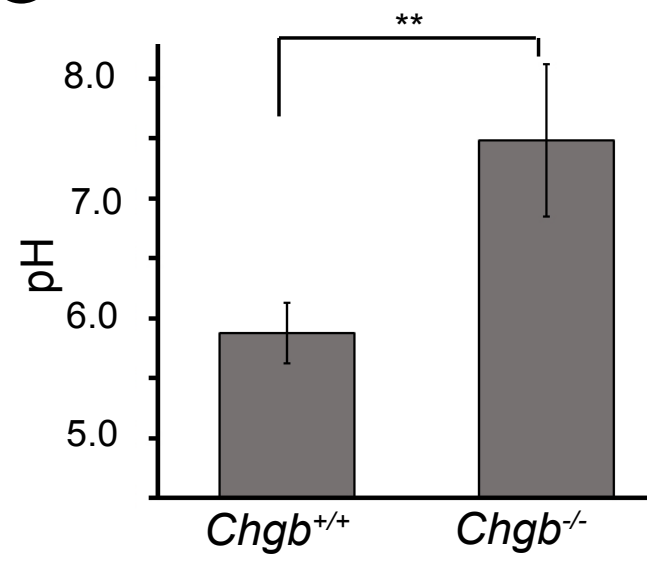


1 Figure 7. A working model for the CHGB anion channel serving as the long-sought $\mathrm{Cl}^{-}$

2 shunt pathway in regulated secretion.

3 (A) $\mathrm{CHGB}$ channel, together with vesicular $\mathrm{H}^{+}$-ATPase, supports normal acidification of

4 secretory granules in insulin-secreting cells (both NS-1 and primary $\beta$-cells). CHGB knockdown

5 impairs acidification and delays cargo maturation (proinsulin-to-insulin conversion), and

6 overexpressing CHGB restores acidification and insulin maturation.

7 (B) In monoamine-secretory cells (PC-12 or dopaminergic neurons), the proton-gradient created

8 during granule acidification is used for $\mathrm{H}^{+}$-coupled loading of catecholamines (e.g. dopamine)

9 into secretory granules. CHGB knockdown impairs acidification and dampens catecholamine

10 loading. Its overexpression restores the monoamine loading.

11

12 


\section{Insulin secretory cells (INS-1 \& $\beta$ - cells)}

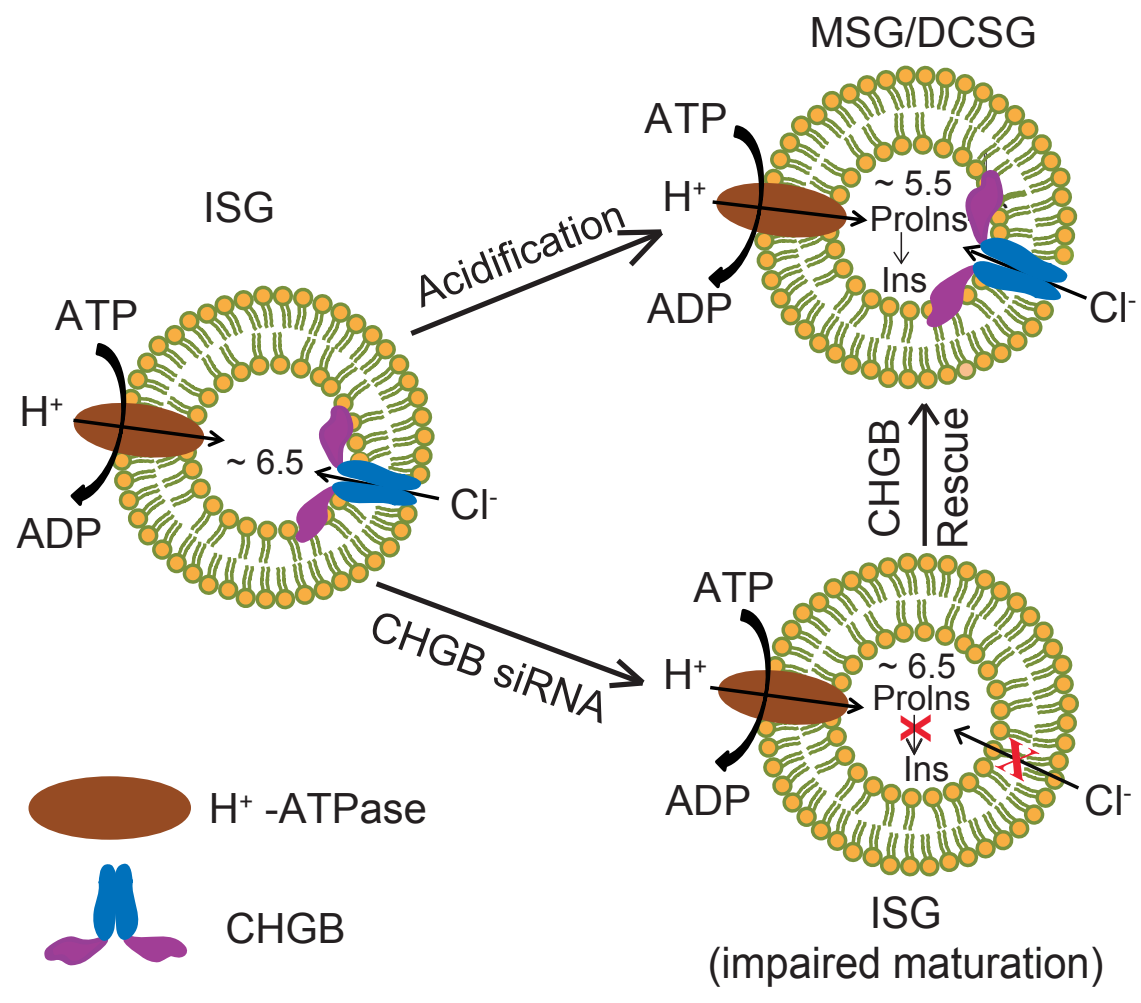

B

Monoamine secretory cells (PC-12 cells)

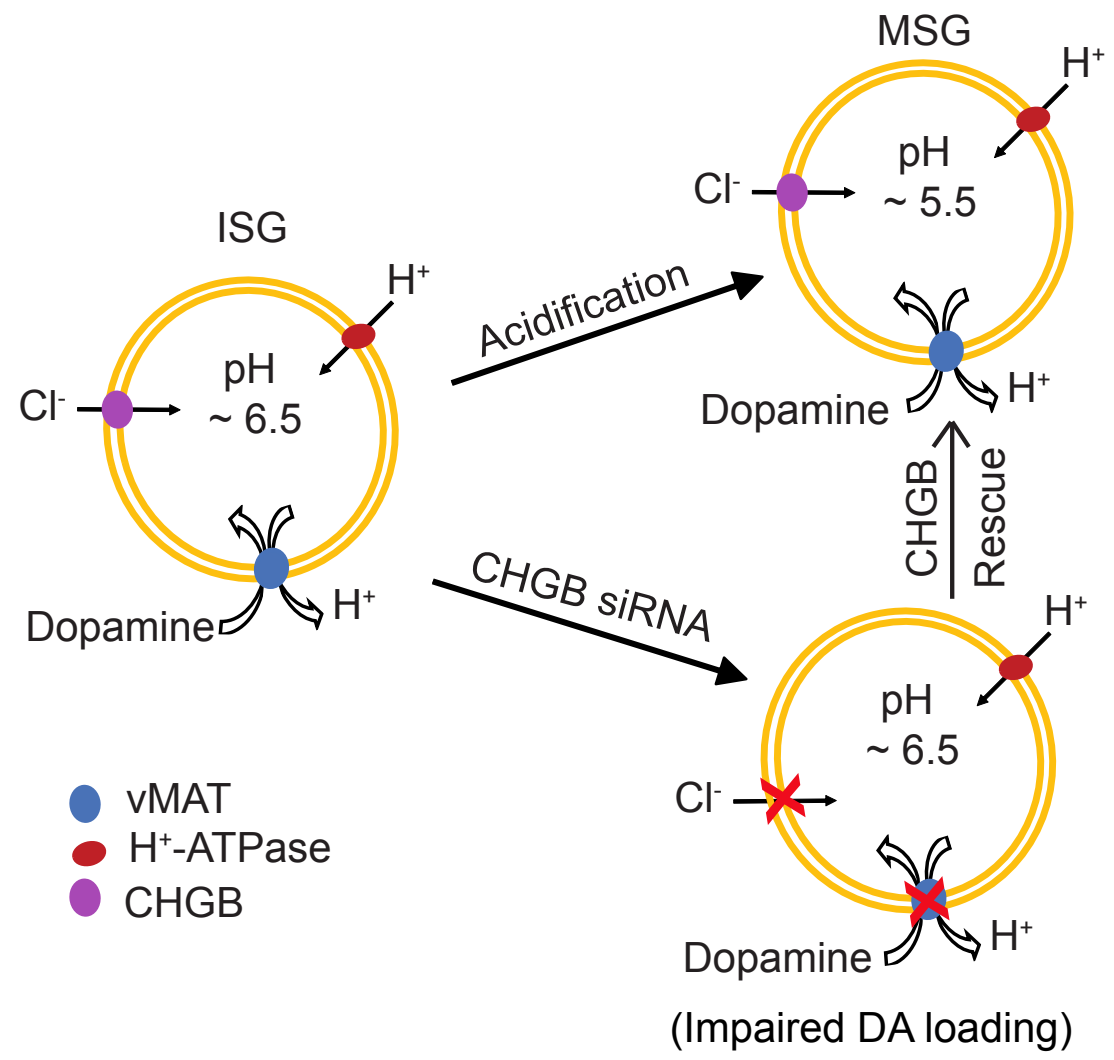




\section{References}

2

31 Bartolomucci A, Possenti R, Mahata SK, Fischer-Colbrie R, Loh YP, Salton SR. The extended granin

4 family: structure, function, and biomedical implications. Endocr Rev 2011; 32:755-797.

52 Dunzendorfer S, Feistritzer C, Enrich B, Wiedermann CJ. Neuropeptide-induced inhibition of IL-16

6 release from eosinophils. Neuroimmunomodulation 2002; 10:217-223.

73 Hur YS, Kim KD, Paek SH, Yoo SH. Evidence for the existence of secretory granule (dense-core

8 vesicle)-based inositol 1,4,5-trisphosphate-dependent Ca2+ signaling system in astrocytes. PLoS One

$9 \quad 2010 ; 5: \mathrm{e} 11973$.

104 Paco S, Margeli MA, Olkkonen VM et al. Regulation of exocytotic protein expression and Ca2+-

11 dependent peptide secretion in astrocytes. J Neurochem 2009; 110:143-156.

125 Shawe-Taylor M, Kumar JD, Holden W et al. Glucagon-like petide-2 acts on colon cancer

13 myofibroblasts to stimulate proliferation, migration and invasion of both myofibroblasts and cancer cells

14 via the IGF pathway. Peptides 2017; 91:49-57.

156 Kumar JD, Holmberg C, Balabanova S et al. Mesenchymal Stem Cells Exhibit Regulated Exocytosis in

16 Response to Chemerin and IGF. PLoS One 2015; 10:e141331.

177 Delevoye C, Marks MS, Raposo G. Lysosome-related organelles as functional adaptations of the

18 endolysosomal system. Current opinion in cell biology 2019; 59:147-158.

198 Curry DL, Bennett LL, Grodsky GM. Dynamics of insulin secretion by the perfused rat pancreas.

$20 \quad$ Endocrinology 1968; 83:572-584.

219 Barg S, Eliasson L, Renstrom E, Rorsman P. A subset of 50 secretory granules in close contact with L-

22 type $\mathrm{Ca} 2+$ channels accounts for first-phase insulin secretion in mouse beta-cells. Diabetes 2002; 51

23 Suppl 1:S74-82.

2410 Hosaka M, Watanabe T. Secretogranin III: a bridge between core hormone aggregates and the 25 secretory granule membrane. Endocr J 2010; 57:275-286. 
111 Dominguez N, van Weering JRT, Borges R, Toonen RFG, Verhage M. Dense-core vesicle biogenesis

2 and exocytosis in neurons lacking chromogranins A and B. J Neurochem 2018; 144:241-254.

312 Zhang K, Biswas N, Gayen JR et al. Chromogranin B: intra- and extra-cellular mechanisms to regulate

4 catecholamine storage and release, in catecholaminergic cells and organisms. J Neurochem 2014; 129:48-

559.

613 Obermuller S, Calegari F, King A et al. Defective secretion of islet hormones in chromogranin-B

7 deficient mice. PLoS One 2010; 5:e8936.

814 Yadav G, Zheng H, Yang Q, Douma LG, Bloom LB, Jiang Q-X. Secretory granule protein

9 chromogranin B (CHGB) forms an anion channel in membrane. Life Science Alliance 2018;

$10 \quad$ 1:e201800139.

$1115 \mathrm{Du} \mathrm{W}$, Zhou M, Zhao W et al. HID-1 is required for homotypic fusion of immature secretory granules

12 during maturation. Elife 2016; 5.

1316 Kogel T, Gerdes HH. Maturation of secretory granules. Results Probl Cell Differ 2010; 50:1-20.

1417 Kakhlon O, Sakya P, Larijani B, Watson R, Tooze SA. GGA function is required for maturation of

15 neuroendocrine secretory granules. Embo J 2006; 25:1590-1602.

1618 Tsuchiya M, Hosaka M, Moriguchi T et al. Cholesterol biosynthesis pathway intermediates and

17 inhibitors regulate glucose-stimulated insulin secretion and secretory granule formation in pancreatic

18 beta-cells. Endocrinology 2010; 151:4705-4716.

1919 Takeuchi T, Hosaka M. Sorting mechanism of peptide hormones and biogenesis mechanism of

20 secretory granules by secretogranin III, a cholesterol-binding protein, in endocrine cells. Curr Diabetes

21 Rev 2008; 4:31-38.

2220 Bearrows SC, Bauchle CJ, Becker M, Haldeman JM, Swaminathan S, Stephens SB. Chromogranin B

23 regulates early-stage insulin granule trafficking from the Golgi in pancreatic islet beta-cells. $J$ Cell Sci

$24 \quad 2019 ; 132$.

2521 Rizo J, Xu J. The Synaptic Vesicle Release Machinery. Annu Rev Biophys 2015; 44:339-367. 
122 Tooze SA, Martens GJ, Huttner WB. Secretory granule biogenesis: rafting to the SNARE. Trends Cell

$2 \quad$ Biol 2001; 11:116-122.

323 Lippert U, Ferrari DM, Jahn R. Endobrevin/VAMP8 mediates exocytotic release of hexosaminidase

4 from rat basophilic leukaemia cells. FEBS Lett 2007; 581:3479-3484.

524 Riedel D, Antonin W, Fernandez-Chacon R et al. Rab3D is not required for exocrine exocytosis but

6 for maintenance of normally sized secretory granules. Mol Cell Biol 2002; 22:6487-6497.

725 Johnson RG, Carty SE, Scarpa A. Coupling of $\mathrm{H}+$ gradients to catecholamine transport in chromaffin

8 granules. Ann N Y Acad Sci 1985; 456:254-267.

926 Johnson RG, Carty S, Scarpa A. A model of biogenic amine accumulation into chromaffin granules

10 and ghosts based on coupling to the electrochemical proton gradient. Fed Proc 1982; 41:2746-2754.

1127 Johnson RG, Scarpa A. Ion permeability of isolated chromaffin granules. The Journal of general

12 physiology 1976; 68:601-631.

1328 Johnson RG, Carty SE, Scarpa A. Catecholamine transport and energy-linked function of chromafffin

14 granules isolated from a human pheochromocytoma. Biochim Biophys Acta 1982; 716:366-376.

1529 Marshansky V, Futai M. The V-type H+-ATPase in vesicular trafficking: targeting, regulation and

16 function. Current opinion in cell biology 2008; 20:415-426.

1730 Forgac M. Vacuolar ATPases: rotary proton pumps in physiology and pathophysiology. Nat Rev Mol

18 Cell Biol 2007; 8:917-929.

1931 Checchetto V, Szabo I. Novel Channels of the Outer Membrane of Mitochondria: Recent Discoveries

20 Change Our View. BioEssays : news and reviews in molecular, cellular and developmental biology

21 2018:e1700232.

2232 Hirschi M, Herzik MA, Jr., Wie J et al. Cryo-electron microscopy structure of the lysosomal calcium-

23 permeable channel TRPML3. Nature 2017; 550:411-414.

$2433 \mathrm{Xu}$ H, Martinoia E, Szabo I. Organellar channels and transporters. Cell Calcium 2015; 58:1-10.

2534 Hordejuk R, Szewczyk A, Dolowy K. The heterogeneity of ion channels in chromaffin granule 26 membranes. Cell Mol Biol Lett 2006; 11:312-325. 
135 Yoo SH, Oh YS, Kang MK et al. Localization of three types of the inositol 1,4,5-trisphosphate

2 receptor/ $\mathrm{Ca}(2+)$ channel in the secretory granules and coupling with the $\mathrm{Ca}(2+)$ storage proteins

3 chromogranins A and B. J Biol Chem 2001; 276:45806-45812.

436 Arispe N, Pollard HB, Rojas E. Calcium-independent K(+)-selective channel from chromaffin granule

5 membranes. J Membr Biol 1992; 130:191-202.

637 Kelly ML, Abu-Hamdah R, Jeremic A, Cho SJ, Ilie AE, Jena BP. Patch clamped single pancreatic

7 zymogen granules: direct measurements of ion channel activities at the granule membrane. Pancreatology

$8 \quad 2005 ; \mathbf{5}: 443-449$.

938 Thevenod F, Braun M, Roussa E, Fuller CM. Molecular characterisation of pancreatic zymogen

10 granule ion channel and regulator proteins involved in exocytosis. J Korean Med Sci 2000; 15

11 Suppl:S51-52.

1239 Montero-Hadjadje M, Vaingankar S, Elias S, Tostivint H, Mahata SK, Anouar Y. Chromogranins A

13 and B and secretogranin II: evolutionary and functional aspects. Acta Physiol (Oxf) 2008; 192:309-324.

1440 Yoo SH. Purification and pH-dependent secretory vesicle membrane binding of chromogranin B.

15 Biochemistry 1995; 34:8680-8686.

1641 Yoo SH. pH- and $\mathrm{Ca}(2+)$-induced conformational change and aggregation of chromogranin $\mathrm{B}$.

17 Comparison with chromogranin A and implication in secretory vesicle biogenesis. J Biol Chem 1995;

$18 \quad 270: 12578-12583$.

1942 Pimplikar SW, Huttner WB. Chromogranin B (secretogranin I), a secretory protein of the regulated

20 pathway, is also present in a tightly membrane-associated form in PC12 cells. J Biol Chem 1992;

$21 \quad 267: 4110-4118$.

2243 Fuchsberger C, Flannick J, Teslovich TM et al. The genetic architecture of type 2 diabetes. Nature

$23 \quad 2016 ; \mathbf{5 3 6}: 41-47$.

2444 Vistnes M, Christensen G, Omland T. Multiple cytokine biomarkers in heart failure. Expert Rev Mol

25 Diagn 2010; 10:147-157. 
145 Rosjo H, Masson S, Latini R et al. Prognostic value of chromogranin A in chronic heart failure: data

2 from the GISSI-Heart Failure trial. Eur J Heart Fail 2010; 12:549-556.

346 Rosjo H, Husberg C, Dahl MB et al. Chromogranin B in heart failure: a putative cardiac biomarker

4 expressed in the failing myocardium. Circ Heart Fail 2010; 3:503-511.

547 Davenport CM, Sevastou IG, Hooper C, Pocock JM. Inhibiting p53 pathways in microglia attenuates

6 microglial-evoked neurotoxicity following exposure to Alzheimer peptides. J Neurochem 2010; 112:552-

7563.

848 Gros-Louis F, Andersen PM, Dupre N et al. Chromogranin B P413L variant as risk factor and

9 modifier of disease onset for amyotrophic lateral sclerosis. Proc Natl Acad Sci U S A 2009; 106:21777-

$10 \quad 21782$.

1149 Tooze SA. Biogenesis of secretory granules in the trans-Golgi network of neuroendocrine and

12 endocrine cells. Biochim Biophys Acta 1998; 1404:231-244.

1350 Diaz-Vera J, Morales YG, Hernandez-Fernaud JR et al. Chromogranin B gene ablation reduces the

14 catecholamine cargo and decelerates exocytosis in chromaffin secretory vesicles. J Neurosci 2010;

15 30:950-957.

1651 Zhang K, Rao F, Rana BK et al. Autonomic function in hypertension; role of genetic variation at the

17 catecholamine storage vesicle protein chromogranin B. Circ Cardiovasc Genet 2009; 2:46-56.

1852 Diaz-Vera J, Camacho M, Machado JD et al. Chromogranins A and B are key proteins in amine

19 accumulation, but the catecholamine secretory pathway is conserved without them. Faseb J 2012; 26:430-

20438.

2153 Benedum UM, Lamouroux A, Konecki DS et al. The primary structure of human secretogranin I

22 (chromogranin B): comparison with chromogranin A reveals homologous terminal domains and a large

23 intervening variable region. Embo J 1987; 6:1203-1211.

2454 Yoo SH. pH-dependent binding of chromogranin B and secretory vesicle matrix proteins to the vesicle 25 membrane. Biochim Biophys Acta 1993; 1179:239-246. 
155 Gasnier C, Lugardon K, Ruh O, Strub JM, Aunis D, Metz-Boutigue MH. Characterization and location

2 of post-translational modifications on chromogranin B from bovine adrenal medullary chromaffin

3 granules. Proteomics 2004; 4:1789-1801.

456 Barbosa JA, Gill BM, Takiyyuddin MA, O'Connor DT. Chromogranin A: posttranslational

5 modifications in secretory granules. Endocrinology 1991; 128:174-190.

657 Taraska JW, Perrais D, Ohara-Imaizumi M, Nagamatsu S, Almers W. Secretory granules are

7 recaptured largely intact after stimulated exocytosis in cultured endocrine cells. Proceedings of the

$8 \quad$ National Academy of Sciences of the United States of America 2003; 100:2070-2075.

958 van Weering JR, Verkade P, Cullen PJ. SNX-BAR-mediated endosome tubulation is co-ordinated with 10 endosome maturation. Traffic 2012; 13:94-107.

1159 van Weering J, Brown E, Mantell J, Sharp T, Verkade P. Studying membrane traffic in high

12 resolution. Methods in Cell Biology — Electron Microscopy of Model Systems 2010:619-648.

1360 Fava E, Dehghany J, Ouwendijk J et al. Novel standards in the measurement of rat insulin granules

14 combining electron microscopy, high-content image analysis and in silico modelling. Diabetologia 2012;

$15 \quad 55: 1013-1023$.

1661 Borges R, Diaz-Vera J, Dominguez N, Arnau MR, Machado JD. Chromogranins as regulators of 17 exocytosis. J Neurochem 2010; 114:335-343.

1862 Howell SL, Fink CJ, Lacy PE. Isolation and properties of secretory granules from rat islets of

19 Langerhans. I. Isolation of a secretory granule fraction. J Cell Biol 1969; 41:154-161.

2063 Syversen U, Waldum HL, O'Connor DT. Rapid, high-yield isolation of human chromogranin A from

21 chromaffin granules of pheochromocytomas. Neuropeptides 1992; 22:235-240.

2264 Stiernet P, Guiot Y, Gilon P, Henquin JC. Glucose acutely decreases $\mathrm{pH}$ of secretory granules in

23 mouse pancreatic islets. Mechanisms and influence on insulin secretion. J Biol Chem 2006; 281:22142-

$24 \quad 22151$.

2565 Fernandez NA, Liang T, Gaisano HY. Live pancreatic acinar imaging of exocytosis using syncollin26 pHluorin. Am J Physiol Cell Physiol 2011; 300:C1513-1523. 
166 Arosio D, Ricci F, Marchetti L, Gualdani R, Albertazzi L, Beltram F. Simultaneous intracellular

2 chloride and pH measurements using a GFP-based sensor. Nat Methods 2010; 7:516-518.

367 Davidson HW, Rhodes CJ, Hutton JC. Intraorganellar calcium and pH control proinsulin cleavage in

4 the pancreatic beta cell via two distinct site-specific endopeptidases. Nature 1988; 333:93-96.

568 Wimalasena K. Vesicular monoamine transporters: structure-function, pharmacology, and medicinal

$6 \quad$ chemistry. Medicinal research reviews 2011; 31:483-519.

769 Nishimura T, Harashima S, Yafang H, Notkins AL. IA-2 modulates dopamine secretion in PC12 cells.

$8 \quad$ Mol Cell Endocrinol 2010; 315:81-86.

970 Phelps EA, Cianciaruso C, Santo-Domingo J et al. Advances in pancreatic islet monolayer culture on

10 glass surfaces enable super-resolution microscopy and insights into beta cell ciliogenesis and

11 proliferation. Scientific reports 2017; 7:45961.

1271 Johnson RG, Pfister D, Carty SE, Scarpa A. Biological amine transport in chromaffin ghosts. Coupling

13 to the transmembrane proton and potential gradients. J Biol Chem 1979; 254:10963-10972.

1472 King KS, Prodanov T, Kantorovich V et al. Metastatic pheochromocytoma/paraganglioma related to

15 primary tumor development in childhood or adolescence: significant link to SDHB mutations. J Clin

16 Oncol 2011; 29:4137-4142.

1773 Dutta S, Mazumdar B, Banerjee KK, Ghosh AN. Three-dimensional structure of different functional

18 forms of the Vibrio cholerae hemolysin oligomer: a cryo-electron microscopic study. J Bacteriol 2010;

$19 \quad$ 192:169-178.

2074 Song L, Hobaugh MR, Shustak C, Cheley S, Bayley H, Gouaux JE. Structure of staphylococcal alpha-

21 hemolysin, a heptameric transmembrane pore. Science 1996; 274:1859-1866.

2275 Mukherjee S, Zheng H, Derebe MG et al. Antibacterial membrane attack by a pore-forming intestinal

23 C-type lectin. Nature 2014; 505:103-107.

2476 Mukherjee S, Partch CL, Lehotzky RE et al. Regulation of C-type lectin antimicrobial activity by a

25 flexible N-terminal prosegment. J Biol Chem 2009; 284:4881-4888. 
177 Sreelatha A, Bennett TL, Carpinone EM et al. Vibrio effector protein VopQ inhibits fusion of V-

2 ATPase-containing membranes. Proc Natl Acad Sci U S A 2015; 112:100-105.

378 Sreelatha A, Bennett TL, Zheng H, Jiang QX, Orth K, Starai VJ. Vibrio effector protein, VopQ, forms

4 a lysosomal gated channel that disrupts host ion homeostasis and autophagic flux. Proc Natl Acad Sci US

$5 \quad A 2013 ; 110: 11559-11564$.

679 Gururaja Rao S, Ponnalagu D, Sukur S et al. Identification and Characterization of a Bacterial

7 Homolog of Chloride Intracellular Channel (CLIC) Protein. Sci Rep 2017; 7:8500.

$8 \quad 80$ Edwards JC. What's a CLIC doing in the podocyte? Kidney international 2010; 78:831-833.

981 Ashley RH. Challenging accepted ion channel biology: p64 and the CLIC family of putative

10 intracellular anion channel proteins (Review). Mol Membr Biol 2003; 20:1-11.

1182 Tulk BM, Schlesinger PH, Kapadia SA, Edwards JC. CLIC-1 functions as a chloride channel when

12 expressed and purified from bacteria. J Biol Chem 2000; 275:26986-26993.

1383 Hossain KR, Turkewitz DR, Holt SA et al. A conserved GXXXG motif in the transmembrane domain

14 of CLIC proteins is essential for their cholesterol-dependant membrane interaction. Biochim Biophys Acta

15 Gen Subj 2019; 1863:1243-1253.

1684 Young JD, Young TM. Channel fluctuations induced by membrane attack complex C5B-9. Molecular

17 immunology 1990; 27:1001-1007.

18 85 Zalman LS, Muller-Eberhard HJ. Comparison of channels formed by poly C9, C5b-8 and the

19 membrane attack complex of complement. Molecular immunology 1990; 27:533-537.

2086 Michaels DW, Abramovitz AS, Hammer CH, Mayer MM. Increased ion permeability of planar lipid

21 bilayer membranes after treatment with the C5b-9 cytolytic attack mechanism of complement. Proc Natl

$22 \quad$ Acad Sci U S A 1976; 73:2852-2856.

2387 Parsons ES, Stanley GJ, Pyne ALB et al. Single-molecule kinetics of pore assembly by the membrane 24 attack complex. Nature communications 2019; 10:2066.

2588 Menny A, Serna M, Boyd CM et al. CryoEM reveals how the complement membrane attack complex 26 ruptures lipid bilayers. Nature communications 2018; 9:5316. 
189 Bayly-Jones C, Bubeck D, Dunstone MA. The mystery behind membrane insertion: a review of the

2 complement membrane attack complex. Philos Trans R Soc Lond B Biol Sci 2017; 372.

390 Kienker PK, Jakes KS, Finkelstein A. Protein translocation across planar bilayers by the colicin Ia

4 channel-forming domain: where will it end? J Gen Physiol 2000; 116:587-598.

591 Weaver CA, Kagan BL, Finkelstein A, Konisky J. Mode of action of colicin ib: formation of ion-

6 permeable membrane channels. Biochim Biophys Acta 1981; 645:137-142.

792 Schein SJ, Kagan BL, Finkelstein A. Colicin K acts by forming voltage-dependent channels in

8 phospholipid bilayer membranes. Nature 1978; 276:159-163.

993 Chen X, He WT, Hu L et al. Pyroptosis is driven by non-selective gasdermin-D pore and its

10 morphology is different from MLKL channel-mediated necroptosis. Cell Res 2016; 26:1007-1020.

1194 Ruhl S, Broz P. The gasdermin-D pore: Executor of pyroptotic cell death. Oncotarget 2016; 7:57481-

1257482.

1395 Liu X, Zhang Z, Ruan J et al. Inflammasome-activated gasdermin D causes pyroptosis by forming

14 membrane pores. Nature 2016; 535:153-158.

1596 Ding J, Wang K, Liu W et al. Pore-forming activity and structural autoinhibition of the gasdermin

16 family. Nature 2016; 535:111-116.

1797 Ruan J, Xia S, Liu X, Lieberman J, Wu H. Cryo-EM structure of the gasdermin A3 membrane pore.

$18 \quad$ Nature 2018; 557:62-67.

1998 Antignani A, Youle RJ. How do Bax and Bak lead to permeabilization of the outer mitochondrial

20 membrane? Curr Opin Cell Biol 2006; 18:685-689.

2199 Uren RT, O'Hely M, Iyer S et al. Disordered clusters of Bak dimers rupture mitochondria during

22 apoptosis. eLife 2017; 6.

23100 Uren RT, Iyer S, Kluck RM. Pore formation by dimeric Bak and Bax: an unusual pore? Philos Trans

$24 \quad$ R Soc Lond B Biol Sci 2017; 372.

25101 Cosentino K, Garcia-Saez AJ. Bax and Bak Pores: Are We Closing the Circle? Trends Cell Biol $26 \quad 2017 ; 27: 266-275$. 
1102 Shrestha A, Mehdizadeh Gohari I, McClane BA. RIP1, RIP3, and MLKL Contribute to Cell Death

2 Caused by Clostridium perfringens Enterotoxin. mBio 2019; 10.

3103 Zhang Y, Han J. Electrophysiologist shows a cation channel function of MLKL. Cell Res 2016;

$4 \quad$ 26:643-644.

5104 Zhang J, Yang Y, He W, Sun L. Necrosome core machinery: MLKL. Cell Mol Life Sci 2016;

$6 \quad 73: 2153-2163$.

7105 Su L, Quade B, Wang H, Sun L, Wang X, Rizo J. A plug release mechanism for membrane

8 permeation by MLKL. Structure 2014; 22:1489-1500.

9106 Wang H, Sun L, Su L et al. Mixed lineage kinase domain-like protein MLKL causes necrotic

10 membrane disruption upon phosphorylation by RIP3. Mol Cell 2014; 54:133-146.

11107 Zhang Y, Lu W, Hong M. The membrane-bound structure and topology of a human alpha-defensin

12 indicate a dimer pore mechanism for membrane disruption. Biochemistry 2010; 49:9770-9782.

13108 Hristova K, Selsted ME, White SH. Interactions of monomeric rabbit neutrophil defensins with

14 bilayers: comparison with dimeric human defensin HNP-2. Biochemistry 1996; 35:11888-11894.

15109 Awang T, Pongprayoon P. The adsorption of human defensin 5 on bacterial membranes: simulation 16 studies. J Mol Model 2018; 24:273.

17110 Chanat E, Weiss U, Huttner WB, Tooze SA. Reduction of the disulfide bond of chromogranin B

18 (secretogranin I) in the trans-Golgi network causes its missorting to the constitutive secretory pathways.

19 Embo J 1993; 12:2159-2168.

20111 Taupenot L, Harper KL, Mahapatra NR, Parmer RJ, Mahata SK, O'Connor DT. Identification of a

21 novel sorting determinant for the regulated pathway in the secretory protein chromogranin A. J Cell Sci

$22 \quad 2002 ; 115: 4827-4841$.

23112 Maritzen T, Keating DJ, Neagoe I, Zdebik AA, Jentsch TJ. Role of the vesicular chloride transporter

24 ClC-3 in neuroendocrine tissue. J Neurosci 2008; 28:10587-10598. 
1113 Guzman RE, Alekov AK, Filippov M, Hegermann J, Fahlke C. Involvement of ClC-3 chloride/proton

2 exchangers in controlling glutamatergic synaptic strength in cultured hippocampal neurons. Front Cell

3 Neurosci 2014; 8:143.

4114 Guzman RE, Grieschat M, Fahlke C, Alekov AK. ClC-3 is an intracellular chloride/proton exchanger

5 with large voltage-dependent nonlinear capacitance. ACS Chem Neurosci 2013; 4:994-1003.

6115 Deriy LV, Gomez EA, Jacobson DA et al. The granular chloride channel ClC-3 is permissive for

7 insulin secretion. Cell Metab 2009; 10:316-323.

8116 Li DQ, Jing X, Salehi A et al. Suppression of sulfonylurea- and glucose-induced insulin secretion in

9 vitro and in vivo in mice lacking the chloride transport protein ClC-3. Cell Metab 2009; 10:309-315.

10117 Yordanov TE, Hipolito VEB, Liebscher G et al. Biogenesis of lysosome-related organelles complex-

111 (BORC) regulates late endosomal/lysosomal size through PIKfyve-dependent phosphatidylinositol-3,5-

12 bisphosphate. Traffic 2019; 20:674-696.

13118 Vukoja A, Rey U, Petzoldt AG et al. Presynaptic Biogenesis Requires Axonal Transport of

14 Lysosome-Related Vesicles. Neuron 2018; 99:1216-1232 e1217.

15119 Barrett A, Hermann GJ. A Caenorhabditis elegans Homologue of LYST Functions in Endosome and

16 Lysosome-Related Organelle Biogenesis. Traffic 2016; 17:515-535.

17120 Lettau M, Kabelitz D, Janssen O. Lysosome-Related Effector Vesicles in T Lymphocytes and NK

18 Cells. Scand J Immunol 2015; 82:235-243.

19121 Yoo SH, So SH, Kweon HS, Lee JS, Kang MK, Jeon CJ. Coupling of the inositol 1,4,5-trisphosphate

20 receptor and chromogranins A and B in secretory granules. J Biol Chem 2000; 275:12553-12559.

21122 Thrower EC, Choe CU, So SH, Jeon SH, Ehrlich BE, Yoo SH. A functional interaction between

22 chromogranin B and the inositol 1,4,5-trisphosphate receptor/Ca2+ channel. J Biol Chem 2003;

$23 \quad 278: 49699-49706$.

24123 Mo M, Hoang HT, Schmidt S, Clark RB, Ehrlich BE. The role of chromogranin B in an animal 25 model of multiple sclerosis. Mol Cell Neurosci 2013; 56:102-114. 
1124 Schmidt S, Mo M, Heidrich FM, Celic A, Ehrlich BE. C-terminal domain of chromogranin B

2 regulates intracellular calcium signaling. J Biol Chem 2011; 286:44888-44896.

3125 Park E, Campbell EB, MacKinnon R. Structure of a CLC chloride ion channel by cryo-electron

4 microscopy. Nature 2017; 541:500-505.

$5126 \mathrm{Lu}$ X, Ding Y, Niu Q et al. ClC-3 chloride channel mediates the role of parathyroid hormone [1-34]

6 on osteogenic differentiation of osteoblasts. PLoS One 2017; 12:e0176196.

7127 Guzman RE, Miranda-Laferte E, Franzen A, Fahlke C. Neuronal ClC-3 Splice Variants Differ in

8 Subcellular Localizations, but Mediate Identical Transport Functions. J Biol Chem 2015; 290:25851-

925862.

10128 Okada T, Akita T, Sato-Numata K, Islam MR, Okada Y. A newly cloned ClC-3 isoform, ClC-3d, as

11 well as ClC-3a mediates Cd-sensitive outwardly rectifying anion currents. Cell Physiol Biochem 2014;

$12 \quad 33: 539-556$.

13129 Huang LY, He Q, Liang SJ et al. ClC-3 chloride channel/antiporter defect contributes to

14 inflammatory bowel disease in humans and mice. Gut 2014; 63:1587-1595.

15130 Zhang H, Li H, Yang L et al. The ClC-3 chloride channel associated with microtubules is a target of 16 paclitaxel in its induced-apoptosis. Sci Rep 2013; 3:2615.

17131 Wang XG, Tao J, Ma MM, Tang YB, Zhou JG, Guan YY. Tyrosine 284 phosphorylation is required 18 for ClC-3 chloride channel activation in vascular smooth muscle cells. Cardiovasc Res 2013; 98:469-478.

19132 Wang $\mathrm{L}, \mathrm{Ma} \mathrm{W}$, Zhu L et al. ClC-3 is a candidate of the channel proteins mediating acid-activated

20 chloride currents in nasopharyngeal carcinoma cells. Am J Physiol Cell Physiol 2012; 303:C14-23.

21133 Qian Y, Du YH, Tang YB et al. ClC-3 chloride channel prevents apoptosis induced by hydrogen

22 peroxide in basilar artery smooth muscle cells through mitochondria dependent pathway. Apoptosis 2011;

$23 \quad 16: 468-477$.

24134 Duan DD. The ClC-3 chloride channels in cardiovascular disease. Acta Pharmacol Sin 2011; 32:675-

25684. 
1135 Ahnert-Hilger G, Jahn R. CLC-3 spices up GABAergic synaptic vesicles. Nat Neurosci 2011;

$2 \quad 14: 405-407$.

3136 Picollo A, Malvezzi M, Accardi A. Proton block of the CLC-5 Cl-/H+ exchanger. J Gen Physiol

$4 \quad 2010 ; 135: 653-659$.

5137 Jentsch TJ, Maritzen T, Keating DJ, Zdebik AA, Thevenod F. ClC-3--a granular anion transporter

$6 \quad$ involved in insulin secretion? Cell Metab 2010; 12:307-308.

7138 Hume JR, Wang GX, Yamazaki J, Ng LC, Duan D. CLC-3 chloride channels in the pulmonary

8 vasculature. Adv Exp Med Biol 2010; 661:237-247.

9139 Feng L, Campbell EB, Hsiung Y, MacKinnon R. Structure of a eukaryotic CLC transporter defines

10 an intermediate state in the transport cycle. Science 2010; 330:635-641.

11140 Volk AP, Heise CK, Hougen JL et al. ClC-3 and IClswell are required for normal neutrophil

12 chemotaxis and shape change. J Biol Chem 2008; 283:34315-34326.

13141 Okamoto F, Kajiya H, Toh K et al. Intracellular ClC-3 chloride channels promote bone resorption in

14 vitro through organelle acidification in mouse osteoclasts. Am J Physiol Cell Physiol 2008; 294:C693-

15701.

16142 Matsuda JJ, Filali MS, Volk KA, Collins MM, Moreland JG, Lamb FS. Overexpression of CLC-3 in

17 HEK293T cells yields novel currents that are pH dependent. Am J Physiol Cell Physiol 2008; 294:C251-

18262.

19143 Mao J, Chen L, Xu B et al. Suppression of ClC-3 channel expression reduces migration of

20 nasopharyngeal carcinoma cells. Biochem Pharmacol 2008; 75:1706-1716.

21144 Habela CW, Olsen ML, Sontheimer H. ClC3 is a critical regulator of the cell cycle in normal and 22 malignant glial cells. J Neurosci 2008; 28:9205-9217.

23145 Accardi A, Miller C. Secondary active transport mediated by a prokaryotic homologue of ClC Cl24 channels. Nature 2004; 427:803-807. 
1146 Gunther W, Luchow A, Cluzeaud F, Vandewalle A, Jentsch TJ. ClC-5, the chloride channel mutated

2 in Dent's disease, colocalizes with the proton pump in endocytotically active kidney cells. Proc Natl Acad

3 Sci U S A 1998; 95:8075-8080. 